Board of Governors of the Federal Reserve System

International Finance Discussion Papers

Number 443

April 1993

\title{
GLOBAL VERSUS COUNTRY-SPECIFIC PRODUCTIVITY SHOCKS AND THE CURRENT ACCOUNT
}

Reuven Glick and Kenneth Rogoff

NOTE: International Fiance Discussion Papers are preliminary materials circulated to stimulate discussion and critical comment. References in publications to International Finance Discussion Papers (other than acknowledgement that the author has had access to unpublished material) should be cleared with the author or authors. 


\begin{abstract}
For G-7 countries over the period 1961-1990, there appears to be a strong and stable negative correlation between annual changes in the current account and investment. Here we explore this correlation using a highly tractable empirical model that distjnguishes between global and country-specific shocks. Tlis cistinction turns out to be quite important empirically, as global shocks account for roughly fifty percent of the overall variance of productivity. An apparent puzzle, however, is that the curren: account seems to respond by much less than investment to countryspecific productivity shocks. Given the near random walk behavior of these shocks, this observation would appear to contradict a central crossequation inequality restriction implied by the intertemporal approach. We show analytically, however, that the theoretically-predicted current account response can be extremely sensitive to small changes in the degree of mean reversion in country-specific productivity; in general, the current account response is more sensitive than is the investment response. Our results thus support the view that there is a significant convergent component to country-specific productivity shocks.
\end{abstract}




\section{Global versus Country-Specific Productivity \\ Shocks and the Current Account}

\section{Reuven Glick and Kenneth Rogoff ${ }^{1}$}

This paper develops an empirical model of the current account to explore the remarkably consistent correlation between investment and the current account deficit, in differences, across major industrialized countries over the post-war period. Though the correlation is negative as the theory predicts, the main puzzle is why, with open capital markets, it is not larger. On average, a rise in investment tends to increase the current account deficit by only one third as much.

Our framework is in the tradition of Sachs (1981), Obstfeld (1986), and Frenkel and Razin (1987) who theoretically analyze the intertemporal effects of government spending and productivity shocks. The main departure here, aside from developing and implementing a (highly tractable) empirical formulation, is the distinction between global and country-specific shocks. Global productivity shocks affect investment but should not have a significant effect on current accounts; we find this to be consistently the case in our structural regressions. The importance of global shocks, which account for roughly fifty per cent of the variance of total productivity, appears to be an important explanation of why the current accountinvestment correlation is not closer to one. But it is not the entire story.

\footnotetext{
${ }^{1}$ Ferleral Reserve Bank of San Francisco and Princeton University respectively. Part of the research for this paper was performed while Rogoff was a visiting scholar at the International Finance Division of the Federal Reserve Board. The authors are grateful to Shaghil Ahmed, David Backus, Marianne Baxter, Maurice Obstfeld, Assaf Razin and seminar participants at the International Finance Division for comments on an earlier draft, and to Robert Marquez for research assistance. The views presented in this paper are those of the authors alone and do not necessarily reflect those of the Federal Reserve Bank of San Francisco or the Board of Governors of the Federal Reserve System. Rogoff has benefitted from the support of the National Science Foundation, the German Marshall Fund of the United States, and the Federal Reserve 3ank of San Francisco.
} 
Even after controlling for global shocks, an interesting puzzle remains. A fundamental implication of the intertemporal model is that a permanent country-sprecific productivity shock will induce a rise in the current account deficit in excess of the: corresponding rise in investment. Because it takes time for the capital stock to acljust, permanent income rises by more than current income; this implies that domestic savings should fall.

Empirically, country-specific productivity shifts indeed tend to be very long-lasting. Using conventional unit root tests, the random walk hypothesis cannot be rejected for any country in our sample. But despite the near random walk behavior of country-specific productivity shocks, we find that empirically their effect on investment tends to be two to three times larger than on the current account. In other words, if one assumes random walk productivity, the data decisively reject a fundamental cross-equation restriction implied by the intertemporal model. Controlling for government consumption shocks does not reverse this result. Allowing for slight mean reversion in country-specific productivity -- convergence -can however, provide a resolution.

With adjustment costs, both the current account and investment depend on the present discounted value of future country-specific shocks. Using closed-form solutions, we are able to show analytically that the impact of the persistence of these shocks on the current account response is always greater. Quantitatively, with a real interest rate of 3 percent, the relative current account response falls by three-fourths when the first-order autocorrelation coefficient for (country-specific) productivity drops from 1.00 to .97 , near the mean of our point estimates. $^{2}$

\footnotetext{
${ }^{2} \mathrm{~A}$ similar sensitivity to persistence arises in the consumption volatility literature. (See Deaton, 1992.)
} 
Section II develops the model and section III contains the empirical results for the random walk productivity case for the Group of Seven (G-7) major industrialized countries. In section IV we relax the random walk restriction, re-estimate the model, and demonstrate why the relative response of the current account depends very nonlinearly on persistence. In section $\mathrm{V}$, we show that the model fits well the stylized facts on the correlations between changes in investment and the current account.

\section{A One Good, Small-Country Model with Adjustment Costs to Investment}

In this section we develop a structural model in which investment and the current account depend on exogenous shocks to productivity. The basic building blocks--a model of investment with adjustment costs and the random walk model of consumption--are quite familiar so our discussion of individuals' and firms' maximization problems will be quite brief. We will show that by using a linear-quadratic approach, one can obtain extremely tractable estimating equations for investment and the current account. Initially, we will focus on the e:fects of country-specific productivity shocks; global shocks and government spending shocks will be incorporated later.

\section{A. Capital Markets}

The representative agent in each country can borrow freely in world capital markets at the riskless (gross) world real interest rate $r$, which is denominated in terms of the single consumption good. If all shocks are country-specific (i.e., uncorrelated with global shocks), then for a small country $r$ may be treated as exogenous. Only riskless bonds are traded 
internationally, so that agents cannot diversify away country-specific shocks. ${ }^{3}$

\section{B. Aggregate Supply}

The representative agent supplies labor inelastically so that net aggregate output $Y$ is given by

$$
Y_{t}=A_{t}^{c} K_{t}^{\alpha}\left[1-\frac{g}{2}\left(\frac{I_{l}^{2}}{K_{t}}\right)\right]
$$

where $K_{t}$ is the capital stock at time $t, A_{t}^{c}$ is the time- $t$ country-specific productivity shock,

and

$$
I_{t}=K_{t+1}-K_{t}
$$

is investment. ${ }^{4}$ The $I^{2} / K$ term in eq. (1) captures adjustment costs in changing the capital stock.

The representative firm chooses the path of $\left\{I_{l}\right\}$ to maximize the present discounted value of future profits discounted at the world interest rate. ${ }^{5}$ The solution to this problem is well known (see, for example, Abel and Blanchard (1986), Meese (1980), or Shapiro (1986)). Taking a linear approximation to the first-order conditions yields ${ }^{6}$

\footnotetext{
${ }^{3}$ Thus our model follows the classic intertemporal approach in which country-specific productivity shocks can affect consumption rather than the complete markets open-economy real business cycle (RBC) approach. For RBC models, see Stockman and Tesar (1990), Backus, Kydland, and Kehoe (1992), and Mendoza (1991). Baxter and Crucini (1992) find that the two approaches yield similar results for cross-country consumption correlations unless the degree of persistence of productivity shocks is very high.

${ }^{4}$ Introducing depreciation slightly complicates the empirical specification below, but does not appear to significantly affect our results. To simplify our exposition here, we omit it.

${ }^{5}$ Our empirical specification implicitly assumes that the covariance of the marginal utility of consumption and investment is constant over time, since country-specific shocks to productivity cannot be diversified.

${ }^{6}$ Implicitly we assume the productivity shocks are homoskedastic, and that the variance terms that would appear in the second-order approximation are constant. Abel and Blanchard (1986) show that for reasonable parameter values a first-order approximation yields virtually the same empirical predictions as the more precise, but much more complicated, second-order approximation.
} 


$$
Y_{t} \cong \alpha_{1} I_{t}+\alpha_{K} K_{t}+\alpha_{A} A_{t}^{c}
$$

and

$$
I_{t} \cong \beta_{1} I_{t-1}+\eta \sum_{s=1}^{\infty} \lambda^{s}\left(E_{t} A_{t+s}^{c}-E_{t-1} A_{t+s-1}^{c}\right)
$$

where in eq. (3) $\alpha_{1}<0$ (due to costs of adjustment), and $\alpha_{K}, \alpha_{A}>0$. In eq. (4), $0<\beta_{1}$ $<1,0<\eta$, and $0<\lambda<1 ; E_{t}$ denotes expectations based on time $t$ information. The first term captures the effects on current investment of lagged productivity shocks, and the second term captures the impact of revisions in expectations about the future path of productivity.

\section{Consuniption}

The representative agent chooses her path of consumption $\left\{C_{l}\right\}$ to maximize

$$
E_{t} \sum_{s=0}^{\infty} \beta^{s} U\left(C_{t+s}\right), \quad U=C-\frac{h}{2} C^{2}
$$

subject to the intertemporal budget constraint

$$
F_{t+1}=r F_{t}+y_{t}-C_{t}
$$

where $y \equiv Y-I$ is net (of investment) income and $F_{t}$ denotes foreign assets entering period $t$. For simplicity, we assume $\beta=1 / r$. The quadratic specification of utility in (5) is, of course, the same as in Hall's (1978) random walk model of consumption. The solution to the maximization problem embodied in (5) and (6) yields ${ }^{7}$

$$
C_{t}=\frac{r-1}{r}\left(F_{t}+E_{t} \sum_{s=0}^{\infty} y_{t+s} / r^{s}\right) \equiv \bar{y}_{t}
$$

As in Hall (1978), the ex-post rate of change of consumption depends only on

\footnotetext{
${ }^{7}$ In deriving (7) it is assumed $r$ is nonstochastic. Otherwise second-order terms would appear in our linearizations. In the empirical work below, we implicitly assume that the variance of productivity shocks is constant over time so that the second-order terms may be treated as constants.
} 
unanticipated movements in permanent net income:

$$
\Delta C_{t}=\left(E_{t}-E_{t-1}\right) \frac{r-1}{r}\left[E_{t} \sum_{s=0}^{\infty} y_{t+s} / r^{s}\right]=\bar{y}_{t}-E_{t-1} \bar{y}_{t}
$$

where $\Delta C_{t} \equiv C_{t}-C_{t-1}$.

\section{Exogenous Country-Specific Productivity Shocks}

It will be assumed that country-specific productivity shocks follow a first-order autoregressive process:

$$
A_{t}^{c}=\rho A_{t-1}^{c}+\epsilon_{t}, \quad 0 \leq \rho \leq 1,
$$

Extending the analysis to higher-order ARMA processes is straightforward.

\section{E. Deriving the Reduced-Form Estimating Equations for the Current Account and Investment when $\rho=1$}

We are now prepared to solve (1) - (9) to derive estimating equations for investment and the current account. For expositional purposes, it is convenient to initially focus attention on the case where $\rho=1$. Aside from the advantage of analytical tractability, the random walk productivity assumption appears to provide a good empirical approximation for all the G-7 countries in our sample (see Table 2 in section II.B below). Later, in section IV, we will consider whether any of our empirical results may be sensitive to this restriction. Combining eqs. (4) and (9) (with $\rho=1$ ) yields simply

$$
\stackrel{(+)}{I_{t}=\beta_{1} I_{t-1}+\beta_{2} \Delta A_{t}^{c}}
$$

where $\beta_{2} \equiv \eta[\lambda /(1-\lambda)]>0$. Since the empirical regularity we seek to explain involves 
changes in investment and the current account, we will subtract $I_{t-1}$ from both sides of eq. (10) to obtain: ${ }^{8}$

$$
\Delta I_{t}=\left(\beta_{1}-1\right) \stackrel{(+)}{(+)} I_{t-1}+\beta_{2} \Delta A_{t}^{c}
$$

We now proceed to obtain a similar reduced-form expression for $\Delta C A$ as a function of $\Delta A^{c}$ and lagged endogenous variables. Differencing the accounting identity for the current account, one obtains

$$
\Delta C A_{t}=(r-1) \Delta F_{t}+\Delta Y_{t}-\Delta I_{t}-\Delta C_{t}
$$

Note that $\Delta F_{t}=C A_{t-1}$, and that $\Delta I_{t}$ is given by (11). $\Delta Y_{t}$ is easily obtained by substituting eq. (2) into the first difference of eq. (3), and then using (11) to solve out for $\Delta I_{i}$ :

$$
\Delta Y_{t}=\left[\alpha_{l}\left(\beta_{1}-1\right)+\alpha_{K}\right] I_{t-1}+\left(\alpha_{l} \beta_{2}+\alpha_{A}\right) \Delta A_{t}^{c}
$$

Substituting out for $\Delta C$ in eq. (12) involves slightly more work. We begin with eq. (8) which gives $\Delta C$ as a function of innovations to permanent (net) income. Using eqs. (11) and (13) to substitute out for $\Delta I$ and $\Delta Y$, and eq. (9) (with $\rho=1$ ), one obtains (see Appendix 1)

$$
\Delta C_{t}=\left\{\frac{\beta_{2}\left[\left(\alpha_{I}-1\right)(r-1)+\alpha_{K}\right]}{r-\beta_{1}}+\alpha_{A}\right\} \Delta A_{t}^{c}
$$

Since $r-\beta_{1}, \alpha_{A}>0$, the coefficient on $\Delta A^{c}$ on the RHS of (14) is necessarily positive provided that $\left(\alpha_{I}-1\right)+\alpha_{K} /(r-1)>0$; this corresponds to the condition that the adjustment

\footnotetext{
${ }^{8}$ Note that our procedure for transforming eq. (10) for $I$ into eq. (11) for $\Delta I$ would have no effect on any error term in (10). We address the error specification of our estimating equations more systematically in section II.I below.
} 
costs to marginal investment do not exceed the present discounted value of the corresponding output gain, which follows from convexity. Since $\alpha_{I}<0$, it follows that $\partial \Delta C / \partial \Delta A^{\prime \prime}>$ $\partial \Delta Y / \partial \Delta A^{c}>0$ (by comparing eqs. (13) and (14)).

The intuition behind the result that the coefficient on the country-specific productivity shock $\Delta A^{c}$ is greater in eq. (14) for consumption than in eq. (13) for output is simple but important. A permanent productivity shock has a greater effect on $\Delta C$ than on $\Delta Y$ because a permanent rise in $A^{c}$ induces investment and leads to a higher future capital stock, thereby causing permanent net income $\bar{y}_{t}$ to rise by more than current gross income $Y_{t}$. Note that if the country were to hold investment constant in response to the shock, then $\bar{y}$ and $Y$ would rise by exactly the same amount. However, since it becomes profitable to raise investment after a positive productivity shock, $\bar{y}$ and hence $C$ must rise by more than $Y$.

Combining eqs. (11) - (14) yields the estimating equation for the current account:

$$
\Delta C A_{t}=\stackrel{(+)}{=} \gamma_{1} I_{t-1}+(-) \stackrel{(+)}{\gamma_{2} \Delta A_{t}^{c}+(r-1) C A_{t-1}}
$$

where

$\gamma_{1} \equiv\left(\beta_{1}-1\right)\left(\alpha_{I}-1\right)+\alpha_{K}>0$, and $\gamma_{2} \equiv \beta_{2}\left[\left(\alpha_{I}-1\right)\left(1-\beta_{1}\right)-\alpha_{K}\right] /\left(r-\beta_{1}\right)<0$.

For exactly the same reasons that the coefficient on $\Delta A^{c}$ is greater in the consumption equation than in the income equation, one can show that the coefficient on $\Delta A^{c}$ in the current account eq. (15) is greater in absolute value than the corresponding coefficient in the investment eq. (11); that is $\left|\partial \Delta C A / \partial \Delta A^{c}\right|>\partial \Delta I / \partial \Delta A^{c}>0 .{ }^{9}$ A permanent rise in productivity not only worsens the current account due to higher investment, but alsc, as we

\footnotetext{
${ }^{9}$ To show that $\gamma_{2} \mid>\beta_{2}$, note that $\left[\left(\alpha_{1}-1\right)\left(1-\beta_{1}\right)-\alpha_{K}\right] /\left(r-\beta_{1}\right)<-1$ iff $\left[\left(\alpha_{1}-1\right)\left(\beta_{1}-1\right)-\alpha_{K}\right]>r-\beta_{1}$ iff $\left(\alpha_{1}-1\right)(r-1)+\left(\alpha_{1}-1\right)\left(\beta_{1}-r\right)+\alpha_{K}>r-\beta_{1}$ iff $\left(\alpha_{1}-1\right)(r-1)+\alpha_{K}>\left(r-\beta_{1}\right) \alpha_{1}$. This final condition holds provided $\left(\alpha_{1}-1\right)(r-1)+\alpha_{K}>0$, which is again the condition that the present discounted value of higher output from investment exceeds the adjustment cost.
} 
have alreadly discussed, because it causes consumption to rise by more than gross output. ${ }^{10}$

Of course, this result can be traced to the random walk productivity shock

assumption. If $\rho=0-$ so that the country-specific productivity shock is temporary -- then

current income would rise by more than permanent income. Since there would be no

investment response to a purely temporary shock, the current account would necessarily

move into surplus. As we shall see, a random walk provides a good empirical approximation

for the productivity shocks, so we will postpone discussion of the $\rho<1$ case until section

IV. Instead, we first introduce global productivity shocks and (global and country-specific)

government spending shocks.

\section{G. Global productivity shocks}

Suppose that in addition to the country-specific component $A^{c}$, the productivity shock contains a global component (common to all countries) $A^{w}$, so that eq. (1) is replaced by

$$
Y_{t}^{c}=\left(A_{t}^{\omega} \bullet A_{t}^{c}\right) K_{t}^{\alpha}\left[1-\frac{g}{2}\left(\frac{l_{t}^{2}}{K_{t}}\right)\right]
$$

for country $c$. If all countries have identical preferences, technology, and initial capital stocks, then the change in a country's current account depends on its country-specific shock $A^{c}$, but not on the global shock $A^{w}$ since the latter impacts on all countries equally. ${ }^{11}$ World

\footnotetext{
${ }^{10}$ Note also that the coefficient $\left(\gamma_{1}\right)$ on $I_{t-1}$ in the $\Delta C A$ equation (15) is positive and larger in absolute value than the corresponding coefficient in the $\Delta I$ equation $\left(1-\beta_{1}\right)$. (Recall that $\alpha_{I}<0$ and $0<\beta_{1}<1$.) A positive level of $I_{t-1}$ causes the current account to improve both because $I_{t}$ tends to revert to equilibrium, and also because lagged investment raises current output. The change in consumption $\Delta C_{t}$ is, of course, unaffected by any variables dated $t-1$ or earlier, including lagged investment.

${ }^{11}$ This assumes zero initial net foreign asset positions, which is a reasonable empirical approximation for the G-7 countries over the sample period.
} 
interest rates rise to bring global savings and investment into equilibrium.

$A^{w}$ does, of course, affect investment, but by less than an idiosyncratic shock of the same duration, since $A^{w}$ affects world interest rates. Equation (11) is then replaced by

$$
\Delta I_{t}=\left(\beta_{1}-1\right) I_{t-1}+\beta_{2} \Delta A_{t}^{c}+\beta_{3} \Delta \mathcal{A}_{t}^{w}
$$

where, if both $A^{w}$ and $A^{c}$ follow random walks $(\rho=1), 0<\beta_{3}<\beta_{2}$ due to the interest rate effect of the global shock. ${ }^{12}$ If, however, the global shock is permanent and the countryspecific shock is sufficiently transitory, then, of course, $\beta_{3}$ may be greater than $\beta_{2}$.

\section{H. Government spending shocks}

Introducing country-specific government (consumption) spending shocks is similarly straightforward. We assume that government spending is purely dissipative (or equivalently that utility is separable in private and public consumption), and is financed by exogenous lump-sum taxes. In this case, country-specific government spending shocks $G^{c}$ should have no effect on $I$, though global government spending shocks $G^{w}$ can have an impact through the real interest rate. ${ }^{13}$ The reverse is true for the current account. Global shocks should not impact on the current account but country-specific government spending shocks may if they are temporary. (A permanent rise in $G^{c}$ will be fully offset by a permanent fall in $C$.) Note that government spending shocks constitute pure aggregate demand shocks in our formulation.

Defining permanent country-specific government spending as

\footnotetext{
${ }^{12}$ Since $\beta_{3}$ arises out of the standard closed-economy model, we do not present an explicit derivation here; see Abel and Blanchard (1986) or Blanchard and Fischer (1989) for further discussion.

${ }^{13}$ Note that global government spending shocks will only affect $I$ if they are transitory; permanent $G^{w}$ shocks have no effect because they do not affect the real interest rate. See Barro (1986). A positive temporary shock to $G^{w}$ should tend to lower $I$, since it raises interest rates.
} 


$$
\begin{aligned}
& \bar{G}_{t}^{c} \equiv[(r-1) / r] E_{t} \sum_{s=0}^{\infty} G_{t+s}^{c} / r^{s}, \text { the current account eq. (15) becomes }{ }^{14} \\
& \Delta C A_{t}=\gamma_{1} I_{t-1}+\gamma_{2} \Delta A_{t}^{c}+\left(\bar{G}_{t}^{c}-E_{t-1} \bar{G}_{t}^{c}-\Delta G_{t}^{c}\right)+(r-1) C A_{t-1}
\end{aligned}
$$

A temporary rise in country-specific government spending $G^{c}$ leads to a deterioration in the current account since permanent after-tax income and therefore consumption declines by less than the: rise in $G^{c}$.

Suppose, for example, that $G^{c}$ is governed by the IMA $(0,1,1)$ process:

$$
G_{t}^{c}=G_{t-1}^{c}+\epsilon_{G t}^{c}-\theta \epsilon_{G t-1}^{c}
$$

Then one can show that in eq. (18), the term $\bar{G}_{t}^{c}-E_{t-1} \bar{G}_{t}^{c}-\Delta G_{t}^{c}$ equals $\theta\left(\epsilon_{G t-1}^{c}-\epsilon_{G l}^{c} / r\right)$.

\section{Error Specification}

As a final preparation for empirical estimation, we introduce additive error terms $\mu_{l t}$, $\mu_{Y l}$, and $\mu_{C l}$ to the investment, output and consumption eqs. (4), (3) and (7). The $\mu$ s are assumed independent of each other (although this assumption is not necessary for identification of the key parameters of interest). The error terms in eqs. (11) and (13) for $\Delta I$ and $\Delta Y$ become $\mu_{l l}$ and $\alpha_{l} \mu_{l l}+\Delta \mu_{Y l}$, respectively. The error term for the $\Delta C$ equation becomes

$$
\left(\frac{\left(\alpha_{I}-1\right)(r-1)+\alpha_{k}}{r-\beta_{1}}\right) \mu_{I t}+\frac{r-1}{r} \mu_{Y t}+\Delta \mu_{C t}
$$

and the error term in the $\Delta C A$ equation (15) becomes

$$
\frac{\left(\alpha_{I}-1\right)\left(1-\beta_{1}\right)+\alpha_{K}}{r-\beta_{1}} \mu_{I t}+\Delta \mu_{Y t}-\left(\frac{r-1}{r}\right) \mu_{Y_{t}}-\Delta \mu_{C t}
$$

With this error specification, we see that $I_{t-1}$ may be treated as a predetermined

\footnotetext{
${ }^{14}$ See Ahmed (1986) for a closely related specification of the effect of $G$ shocks on the current account.
} 
variable in the regression for $\Delta C A_{\mathfrak{t}}$, but $C A_{t-1}$ is endogenous.

\section{Empirical Results}

Before turning to our estimates of structural equations for the current account and investment, it is helpful to first explore some simple correlations between these tvro variables. There is, in fact, a substantial literature starting from Sachs (1981) that attempts to use non-structural current account investment equations to draw inferences on international capital mobility.

Using long-term averages of cross-country data, Sachs $(1981,1983)$ argues that for OECD countries there is indeed a high negative correlation between these two variables, casting doubt on Feldstein and Horioka's (1980) conclusion that capital markets are relatively insular. ${ }^{15}$ Subsequent writers, however, including Penati and Dooley (1984), Tesar (1991), and others find that Sachs' correlations are quite sensitive to a couple of outliers; the general conclusion of this literature is that any correlation is tenuous at best.

\section{A. Reduced-form Regressions for $\triangle C A$ on $\Delta I$}

Is it indeed the case that the empirical correlation between investment and current

\footnotetext{
${ }^{15}$ Sachs argues that the observed non-structural correlations may be caused by productivity shocks; the structural equations presented here support his conjecture. Of course, a strong negative correlation between current accounts and investment only provides evidence on the degree of capital mobility if one is willing to make scime very strong identifying assumptions. It is not enough to assume that the only driving variable is productivity shocks; it is necessary that they be permanent and not transitory, country-specific and not global. Even if the productivity shocks are permanent, country-specific government spending shocks (and more generally demand shocks) reduce the correlation by effecting the current account without affecting investment. Shocks to non-traded goods productivity, on the other hand, may affect investment without having a significant impact on the current account; see Tesar (1993).
} 
accounts is so weak? One might argue that the type of decade-average data that is the focus of the post-Sachs literature looks at too long a horizon to capture the kind of dynamic effects emphasized by the model used here. In Table 1 below, which uses annual time series data instead of cross-country data, we see that the change in the current account exhibits a strong and consistint negative correlation with the change in investment. ${ }^{16}$ For the G-7 industrialized countries in the top half of the table,,$^{17}$ regressing $\Delta C A$ on $\Delta I$ for the years $1961-90$ yields coefficients ranging from -.16 to -.55 , averaging -.36 ; all the coefficients are significant at better than 5 percent. The negative correlation between $\Delta C A$ and $\Delta I$ generally remains intact across the sub-periods 1961-74 and 1975-1990, rising slightly in the second half of the sample. Unreported regressions for the remaining sixteen OECD countries over the full period 1961-90 yield negative coefficients in all cases. In all but three cases, the coefficients are highly significant. ${ }^{18}$

Overall, the time series regressions on differences yield a remarkably consistent relationship between changes in current accounts and investment. The regression coefficient is well below one, but is impossible to draw any inferences on the validity of the intertemporal model without a more detailed investigation of the sources of the shocks.

\section{B. Construction and Time Series Properties of $A^{c}$ and $A^{w}$}

Our method for constructing Solow residuals for productivity uses data published by

\footnotetext{
${ }^{16}$ The coristruction of all variables is described in Appendix 2. There is also evidence of negative correlation in the levels regressions, though it is less robust across time and countries. Roubini (1990) finds evidence of a negative correlation when one includes budget deficits in the non-structural current-account investment level regressions.

${ }^{17} \mathrm{GDP}$ or GNP deflators are used to construct real variables.

${ }^{18}$ See Glick and Rogoff (1992). The point estimates for the smaller countries tend to be slightly larger on average than for the larger G-7 countries. The negative coefficients are significant for Austria, Denmark, Finland, Greece, Iceland, Ireland, Norway, Portugal, Spain, Sweden, Switzerland, Australia and New Zealand. They are not significart at the 5 percent level for Belgium, the Netherlands, and Turkey.
} 
the Bureau of Labor Statistics (BLS) on output and employment hours in manufacturing for major industrialized countries, 1960-90 (see Appendix 2). Following Backus, Kehoe, and Kydland (1992), we form productivity measures as the residuals from Cobb-Doublas production functions:

$$
\ln Y-\pi \ln L-(1-\pi) \ln K
$$

where $\pi$, the share of labor in manufacturing output, is based on data from the OECD intersectoral data base. ${ }^{19}$ Capital, $K$, which is not measured, is proxied by a trend term. Given the well-known problems in constructing comparable capital stock measures in crosscountry data (see, for example, the discussion in Griliches (1988)), the BLS-based Solow residual measure would seem to be a good starting point for testing the model.

One can obtain estimates of Solow residuals that (attempt to) control for capital inputs from the OECD international sectoral data base (see Appendix 2), but only for 1971)-85. Since our model emphasizes dynamic issues, we were reluctant to use these as our main measure. In any event, Backus, Kehoe, and Kydland argue that the capital-input adjustment should not produce radically different results since, for United States data, short-term movements in capital appear to be small relative to short-term movements in output. As Figure 1 illustrates, the two measures are in fact highly correlated for all the countries in our sample. We will later show that results based on the OECD total factor productivity residuals over the shorter time period are very similar to the results ones obtained with the BLS-based residuals over the full sample.

The main justification for our focus on manufacturing sector productivity is that far

\footnotetext{
${ }^{19}$ See Meyer-zu-Schlochtern (1988) and Englander and Mittelstädt (1988). The estimates for $\pi$ used are labor share in the traded goods sector: United States, .64; Japan, .62; Germany, .61; France, .68; Italy, .4!; U.K., .59; Canada, .63; and are taken from Stockman and Tesar (1990).
} 
more arcurate cross-country data are available for manufacturing than for services,

particularly over the earlier part of the sample. Productivity in services is notoriously

difficult to measure, and international comparisons are further complicated by the high

variability in the relative price of non-traded goods across countries.

Our world productivity measure is formed by taking a GNP-weighted average of the seven individual-country measures, ${ }^{20}$ and the country-specific component is then formed as the deviation from the global average. ${ }^{21}$ Table 2 presents Dickey Fuller unit root tests (with a constant and trend) for our productivity measures for the eight countries in the sample, and for the world average. In none of the cases is one able to reject the unit root hypothesis at standard significance levels. ${ }^{22}$ The third column of the table presents estimates for a firstorder autoregressive process. As one can see, the point estimates of $\rho$ are all quite close to one.

The estimates in Table 2 suggest that our earlier assumption that country-specific shocks follow a random walk is at least plausible. Note that by imposing that $\rho=1$, we can

\footnotetext{
${ }^{20}$ The weights were constructed from each country's share of total GDP in 1975, where local currency GDP figures were converted to dollars by the average dollar exchange rate for the year.

${ }^{21} W_{e}$ also considered a more elaborate approach to decomposing $A$ into $A^{c}$ and $A^{w}$. We regressed $A$ for each country on a GNP-weighted average of $A\left(A^{\dagger}\right)$ for the other six countries, treating the residual as the country-specific component. We found in all cases that one could not reject the hypothesis that both $A$ and $A^{f}$ have unit roots, and that they' are not cointegrated. The more elaborate procedure gives very similar results in our current account and investment equations. The two approaches to decomposing $A$ become equivalent for a small country.

${ }^{22}$ In addition to the Dickey-Fuller test, we also employed the Phillips-Perron test with similar results. Another approacl, , based on Levin and Lin (1992) tests the joint hypothesis that there is a unit root in all of the countryspecific productivity series. The $\Delta A^{w}$ regression in this method allows for different coefficients across countries on all variables (intercept and trend terms) except $A_{t-1}^{c}$. With this test, one still cannot in fact reject (at the 5 percent level) the joint hypothesis that $\rho=1$ for all the countries. (Because the seven country-specific productivity series are linearly dependent by construction, it was necessary to drop one of the countries from the joint test.) Finally, we tested the unit root hypothesis against the alternative of a deterministic trend with a break, based on the procedure proposed by Christiano (1992), which does not impose priors on the point in time where the break occurs. One cannot reject the hypothesis of a unit root in favor of a trend break for any of the countries at the 10 percent level of significance. For a version of the test corresponding to an augmented Dickey-Fuller regression, one can reject the unit root null at the 5 percent level for Italy and 7 percent for the U.K. (These results included the Netherlands in the construction of $\Delta A^{w}$.)
} 
avoid the issue of how uncertainty over $\rho$ affects standard errors in the current account and investment equations. In section IV, however, we tackle the more general serial correlation case and are thus able to test the robustness of our results. ${ }^{23}$

It must be emphasized that the exogeneity of productivity shocks is central to structural interpretation of the results below. Though often imposed in modern empirical macroeconomics (e.g., in the real business cycle literature), the assumption that the economy is operating along its equilibrium production function is admittedly a strong one. It has led to important insights in other contexts and we hope to persuade the reader that the same is true here.

\section{Structural Estimates of the $\Delta C A$ and $\Delta I$ equations}

We are now prepared to estimate the central structural equations of our model, eqs. (15) and (17) for $\Delta C A$ and $\Delta I$. Table 3 presents individual country results under the assumption $\rho=1 .^{24}$

For $\Delta I$, the coefficients on $\Delta A^{c}$ and $\Delta A^{w}$ are all of the correct sign and are significant at the 5 percent level in almost 80 percent of the cases. The Ljung-Box Q-statistic does indicate serial correlation for Germany and the U.K. Table 3a presents conditional heteroskedasticity and autocorrelation-consistent standard errors; the results are quite similar

\footnotetext{
${ }^{23}$ There does appear to be some residual correlation in a couple of the series even after taking first differences, especially in $\Delta A^{w}$. Estimating a first order MA process in $\Delta A^{w}$ yields a point estimate of .52 (positive serial correlation), with a standard error of .16. There also appears to be some positive serial correlation in $\Delta A^{c}$ for France, Germany and the U.K., though less than for $\Delta A^{w}$. (These results included the Netlerlands in the construction of $\Delta A^{w}$.)

${ }^{24}$ The results are not sensitive to the inclusion of time trends in the $\Delta C A$ regressions, but we excluded them on a priori grounds. The $\Delta I$ results are only marginally worse without trends, though the results for the U.S. are actually markedly better. To facilitate the cross-country comparison of the coefficients on productivity (and trend) terms, for each country these variables were multiplied by the mean of local real GDP or GNP civer the sample period. This gives the reported coefficients on $\Delta A^{c}$ and $\Delta A^{w}$ the interpretation of the change in the left-hand side variable as a percent of mean GNP in response to a 1 percent increase in productivity.
} 
to those in Table $3{ }^{25}$ The fact that the coefficients on $\Delta A^{w}$ are typically larger than for $\Delta A^{c}$ in the investment equation might be attributable to the positive serial correlation in the first difference of the world productivity shocks. The coefficients on the lagged investment level, $I_{t-1}$, are generally not significant.

Table 3 also presents results for the $\Delta C A$ equation. To deal with possible simultaneity of $C A_{t-1}$ in (15), we constrain its coefficient to equal its theoretically-predicted value $r-1 .{ }^{26}$ Given the near random walk behavior of the country-specific productivity shocks one would expect the estimated coefficients on $\Delta A^{c}$ to be negative, as indeed they are in all cases; Except for France and Germany, the coefficients are all significant at the 10 percent: level or better. As we discuss in Appendix 2, French current account data is available on a consistent basis only since 1967 so the French results are based on a much smaller sample. Again, results reported in Table 3a based on conditional heteroskedasticity and autocorrelation-consistent standard errors are quite similar. The model also predicts that world productivity shocks, $\Delta A^{w}$, should have no effect on current accounts since they affect all countries equally. This hypothesis cannot be rejected for any country except the United Kingdom, but even for the U.K. the country-specific shock has a much larger effect. It should be noted that the seven countries included in our proxy for world productivity shocks, while constituting a significant share of world output, provide somewhat less than complete world coverage. Thus, one might not expect the coefficient on $\Delta A^{w}$ to literally be zero. It should however, be much smaller than the coefficient on $\Delta A^{c}$.

\footnotetext{
${ }^{25}$ These results are obtained using the ROBUSTERRORS option to the LINREG command in RATS, with $D A M P=1$ and $L=2$. This provides Newey-West estimates of the covariance matrix corrected for heteroskedasticity and for serial correlation in the form of a moving average of order 2 .

${ }^{26}$ As our proxy for $r$, we use the real world interest rate series constructed by Barro and Salai-Martin (1990). Fluctuations in $(r-1) C A_{t-1}$ are quite small relative to fluctuations in $\Delta C A_{t}$.
} 
Table 4 reports results for the full pooled time-series cross-section data set with and without country-specific time trends. ${ }^{27}$ As in the individual country regressions, the coefficients in the $\Delta I$ equations are of the correct sign, and all are highly significant. $\Delta A^{c}$ is negative in the pooled $\Delta C A$ regressions, and is also highly significant. The point estimates for the world shock $\Delta A^{w}$ remain small in the pooled $\Delta C A$ equations and, as the model predicts, are insignificantly different from zero.

The main puzzle in Tables 3 and 4 lies in the relative magnitudes of the coefficients on $\Delta A^{c}$ in the $\Delta I$ and $\Delta C A$ equations. Both in Table 4 , and in the individual country results in Table 3, the coefficient on $\Delta A^{c}$ is smaller in absolute value in the current account regressions than in the $\Delta I$ regressions. For the pooled results, it is less than half as large. Given the evidence in Table 2 that productivity shocks (nearly) follow random walks, one might expect the current account response to be larger than the investment response, since consumption should move by more than output; we return to this issue in section IV below. Similarly, the coefficient on $I_{t-1}$ in the $\Delta C A$ equation in Table 4, though of the correct sign, is smaller rather than larger (in absolute value) than the corresponding coefficient in the $\Delta I$ equation.

Our empirical analysis thus far has focused entirely on supply shocks: In the next section we attempt to control for changes in government spending, which constitutes one form of demand shock.

\footnotetext{
${ }^{27}$ The pooled results are estimated using the SUR command in RATS, a GLS system procedure, with equality restrictions imposed across equations, excluding the constants and time trends. To adjust for cross-country heteroskedasticity and to allow the pooling of data in different currency units, we scaled all variables in each equation in the system by the standard error of the corresponding OLS country regression. In addition, as in the individual-country OLS regressions, variables without units, such as productivity changes and trend terms, were multiplied by the mean of local real GNP or GDP over the sample period. We used the SUR option ITER which begins with estimates of cross-country covariances based on the residuals from individual country OLS regressions and recomputes the covariances and system equation estimates iteratively. We set a maximum of 25 iterations, but all results converged before reaching this limit.
} 


\section{Temporary government spending shocks}

Recall that in theory, permanent country-specific government spending shocks have no effect on investment, whereas global government spending shocks have no effect on current accounts. ${ }^{23} G^{c}$ shocks can affect $\Delta C A$, and $G^{w}$ shocks can affect $\Delta I$, but in each case only if they are temporary.

To estimate temporary shocks to government spending, we estimate the ARIMA $(0,1,1)$ process given in eq. (19) above, again forming $G^{w}$ as a weighted average of individual-country $G s$, normalized by GNP. ${ }^{29}$ Given our assumption that $\Delta G$ follows an $\operatorname{MA}(1)$ process, $\left(\bar{G}_{t}^{c}-E_{t-1} \bar{G}_{t}^{c}-\Delta G_{t}^{c}\right)$ is then given by the formula below eq. (19), $\theta^{c}\left(\epsilon_{G t-1}^{c}-\epsilon_{G t}^{\prime} / r\right) . \quad \bar{G}_{t}^{w}-E_{t-1} \bar{G}_{t}^{w}$, the temporary component of changes in $G^{w}$, is given by $\left(r-\theta^{w}\right) \epsilon_{G l}^{w} / r$. The pooled time series cross-section results are presented in Table 5, where $G$ is measured by real government consumption (see Appendix 2); the $\theta$ 's are allowed to vary across countries. ${ }^{30}$ The coefficients on $\Delta A^{c}, \Delta A^{w}$, and $I_{t-1}$ remain exactly as before, and the $G$ shocks do not enter significantly. Individual country regressions (not reported) are also largely unaffected by the inclusion of $G$ shocks. ${ }^{31}$ The fact that government spending appears to have relatively little impact may be due to the difficulty of extracting the temporary component of changes in $G$. In any event, the main conclusion here is that our

\footnotetext{
${ }^{28}$ It would be interesting to extend the analysis to include government investment and its effects on the production function.

${ }^{29}$ To form $G^{w}$, we normalized each country's $G$ by the country's average level of GNP in the period, and then formed a world index using 1975 nominal dollar GNP weights.

${ }^{30}$ We measured the $r$ in the $G$ shock formulas by the mean over the period of the world real interest rate constructed by Barro and Sala-i-Martin (1990).

${ }^{31}$ To check the robustness of these results, we also entered $\Delta G$ and $\Delta G^{w}$ in raw form into the $\Delta C A$ and $\Delta I$ equations, respectively, but they remain insignificant. We also tried controlling for world interest rates directly in the $\Delta C A$ and $\Delta I$ equations using the Barro and Sala-i-Martin (1990) measure of world real interest rates; again the productivity coefficients were little affected.
} 
findings on productivity shocks are largely unaffected by controlling for government consumption shocks.

\section{E. Alternative Empirical Measures of Productivity}

In addition to our BLS-based Solow residual estimates, we tried two alternative measures of productivity. The first was straight output/worker hour, without attempting to adjust for decreasing returns to labor inputs. The results are qualitatively extremely similar to those presented above, both for the time series of productivity and for Tables 3 and 4 .

Next, we used data on total factor productivity in manufacturing from the OECD international sectoral data base, available for the years 1970-1985. These estimates attempt to account for changes in capital. Table 6 presents pooled results corresponding to those in Table 4 for the BLS-based Solow residual estimates. The results are extremely similar to those in Table 4, except that the coefficients on both local and global productivity are somewhat larger in Table $6{ }^{32}$ The coefficient on $\Delta A^{w}$ is actually significant in the $\Delta C A$ regression with a time trend, but it is much smaller in magnitude than the coefficient on the country-specific shock, $\Delta A^{c}$. As mentioned above, one possible rationale why $\Delta A^{w}$ might enter significantly with a very small coefficient is that the seven large industrialized countries here do not quite constitute 100 percent of world GNP, even among countries with relatively open capital markets. The individual-country results are also qualitatively similar, with only slightly fewer coefficients significant at the 5 percent level, due in part to the shorter sample.

\footnotetext{
${ }^{32} \mathrm{We}$ also estimated the regressions in Table 6 using business sector total factor productivity despite the misgivings expressed above. For the $\Delta I$ equation with a time trend we obtained estimates of 1.08 for $b_{1}$ and .64 for $b_{2}$ with marginal significance levels of .00 in both cases. For the $\triangle C A$ equation without a time trend, we obtained estimates of -.08 for $b_{1}$ and -.04 for $b_{2}$ with marginal significance levels of .04 and .44 , respictively. It is not surprising that $\beta_{2}$ is larger relative to $\gamma_{2}$ when productivity is measured using the overall business sector rather than manufacturing; non-traded goods constitute a much smaller share of manufacturing. (These regressions included the Netherlands in the construction of $\Delta A^{w}$ and in the pooled country estimates.)
} 
Note that the coefficients on $\Delta A^{c}$ in the $\Delta C A$ and $\Delta I$ equations are actually much closer in magnitude in Table 6 than in Table 4, though they are tightly estimated and remain smaller in the $\triangle C A$ equations. As a final check, we present in Table 7 pooled estimates using the BLS-based Solow residuals for the post oil-shock period. Overall, the results are similar to the OECD-based results for the recent period in Table 6.

\section{Mean-Reverting Country-Specific Productivity Shocks $(\rho<1)$}

In this section, we explore the sensitivity of our results to the assumption that country-specific productivity shocks follow a random walk. ${ }^{33}$ While in section III. $B$ we could not reject the $\rho=1$ hypothesis for any country using standard unit root tests, it is well known that these tests generally lack power against the alternative of a $\rho$ slightly less than one; the alvailable time series are simply too short to give reliable estimates for the low frequencies. Moreover even if country-specific productivity shocks contain a random walk component, it seems quite likely that they would contain a significant mean-reverting component as well. If one cannot separate the two components empirically, then the estimated consumption response will be a weighted average response. ${ }^{34}$

In section $A$ below, we ask whether relaxing the $\rho=1$ restriction would reverse our conclusion that empirically, unanticipated productivity shocks have a greater impact on investment than on the current account; it turns out that the estimated responses change very little. Nevertheless, as we argue in section $B$, allowing for $\rho$ slightly less than one can

\footnotetext{
${ }^{33}$ From a theoretical perspective, our empirical results should not be particularly sensitive to the time series process followed by global shocks since the current account is zero regardless.

${ }^{34}$ That is, if one thought of productivity shocks as being the sum of a permanent component and a temporary component, consumers would still expect to see some mean reversion, on average. (See Quah, 1990.)
} 
dramatically impact our cross-equation restriction. We show analytically that the current account response to productivity shocks is likely to be hypersensitive to small changes in their persistence.

\section{A. Deriving Estimating Equations for Innovations in Investment and the Current Account}

Deriving the impact effect of shocks on investment is again straightforward. Subtract $t-1$ expectations from both sides of eq. (4) and evaluate the resulting expression to obtain: (Appendix 1 contains the formal derivations for this section)

$$
\tilde{I}_{t}=\beta_{2}^{\prime} \epsilon_{t}
$$

where $\sim$ denotes the revision of expectations operator $E_{t}-E_{t-1}, \tilde{I}_{t}$ is the innovation to investment, $\beta_{2}^{\prime} \equiv \eta \lambda \rho /(1-\lambda \rho)$, and $\epsilon_{t}=\tilde{A}_{t}^{c}=A_{t}^{c}-\rho A_{t-1}^{c}$ is the country-specific productivity shock (see eq. (9)). Note that $\partial \beta_{2}^{\prime} / \partial \rho<0$ for $0<\rho<1$; when $\rho=0$, then $\beta_{2}^{\prime}=0$. If the shock is entirely transitory, there is no investment response.

As before, the corresponding equation for the unanticipated change in the current account $\tilde{C A}=\tilde{Y}-\tilde{I}-\tilde{C}$ (note $\tilde{F}_{-1}=0$ ), must be constructed from its component parts. ${ }^{35} \tilde{I}$ is given by eq. (22); $\tilde{Y}$ can be derived using eqs. (3) and (22),

$$
\tilde{Y}_{t}=\left(\alpha_{A} \beta_{2}^{\prime}+\alpha_{A}\right) \epsilon_{t}
$$

where we have used the fact that $\tilde{K}_{t}=0$. Finally, the effect of $\epsilon$ on permanent income -- and therefore on $\tilde{C}(=\Delta C)-$ is given by (see Appendix 1$):^{36}$

\footnotetext{
${ }^{35}$ Note that net foreign assets $F_{1}$ are predetermined.

${ }^{36}$ Note that when $\rho=0$, eqs. (23) and (24) imply $\tilde{C}=\frac{r-1}{r-\rho} \alpha_{A} \epsilon<\alpha_{A} \epsilon=\tilde{Y}$. As we have already discussed, the current account moves into surplus in response to a purely transitory shock.
} 


$$
\tilde{C}_{t}=\delta_{2}^{\prime} \epsilon_{t}
$$

where

$$
\delta_{2}^{\prime} \equiv \frac{r-1}{r-\rho}\left[\beta_{2}^{\prime} \frac{\left(\alpha_{1}-1\right)(r-1)+\alpha_{K}}{r-\beta_{1}}+\alpha_{A}\right]>0
$$

Combining eqs. (22)-(24) yields

$$
\tilde{C A_{t}} \equiv \gamma_{2}^{\prime} \epsilon_{t}
$$

where

$$
\begin{aligned}
\gamma_{2}^{\prime} & \equiv\left(\alpha_{1}-1\right) \beta_{2}^{\prime}+\alpha_{A}-\delta_{2}^{\prime} \\
& =\alpha_{A} \frac{1-\rho}{r-\rho}+\beta_{2}^{\prime}\left(\alpha_{1}-1\right)-\frac{r-1}{r-\rho} \beta_{2}^{\prime} \frac{\left(\alpha_{I}-1\right)(r-1)+\alpha_{K}}{r-\beta_{1}}
\end{aligned}
$$

It is easy to see that $\partial \gamma_{2}^{\prime} / \partial \rho>0$ (for $0<\rho<1$ ); that is, the lower the serial correlation in the productivity disturbance, the smaller the increase in the current account deficit. For $\rho$ small enough, $\gamma_{2}^{\prime}$ must eventually become positive.

Of course, eqs. (22) and (25) cannot be estimated directly since $\tilde{I}$ and $\tilde{C A}$ are not directly observable. Noting that $\Delta I_{t}=\tilde{I}_{t}+E_{t-1} I_{t}-I_{t-1}$, one can use eq. (4) to transform eq. (22) into

$$
\begin{gathered}
\Delta I_{t}=\beta_{2}^{\prime} \epsilon_{t}+\left(\beta_{1}-1\right) I_{t-1}+\beta_{2}^{\prime}(\rho-1) A_{t-1}^{c} \text {, or } \\
\Delta I_{t}=\left(\beta_{1}-1\right) I_{t-1}+\beta_{2}^{\prime} \Delta A_{t}^{c}
\end{gathered}
$$

which is exactly the same as eq. (11) which we have already estimated, except that $\beta_{2}$ is replaced by $\beta_{2}^{\prime}$ ! (With a higher order autoregressive process, more lags of $A^{c}$ would enter into eq. (26).) Thus we do not have to alter our investment equation at all to generalize the 
empirical analysis to the $\rho<1$ case.

The current account equation, however, must be modified slightly. Noting that $\Delta C A_{t}=\tilde{C A_{t}}+E_{t-1} C A_{t}-C A_{t-1}$ and adding $E_{t-1}(Y-I-C)_{t}-(Y-I-C)_{t-1}+(r-1)\left(F_{t-1}-F_{t-2}\right)$ to both sides of eq. (25) yields (after some manipulation; see Appendix 1):

$$
\Delta C A_{t}=\gamma_{1} I_{t-1}+\gamma_{2}^{\prime} A_{t}^{c}+\gamma A_{t-1}^{c}+(r-1) C A_{t-1}
$$

where $\gamma_{1} \equiv\left(\beta_{1}-1\right)\left(\alpha_{1}-1\right)+\alpha_{K}, \gamma_{2}^{\prime}$ is the same as in eq. (25), and $\gamma \equiv-\gamma_{2}^{\prime}+(\rho-1) \delta_{2}^{\prime}$, where $\delta_{2}^{\prime}$ is the coefficient on $\epsilon_{t}$ in the $\tilde{C}$ equation (24). Intuitively, the reason why $A_{t}^{c}$ has the same coefficient in eq. (27) as does $\epsilon_{t}$ in eq. (25) is that anticipated productivity depends on $A_{t-1}^{c}$. Therefore, once the direct and indirect effects of $A_{t-1}^{c}$ are controlled for, $A_{t}^{c}$ affects the current account only through its unanticipated component.

The system of equations for empirical estimation in the $\rho<1$ case is thus given by equations (26), (27) and (9) (the AR process for country-specific productivity). The extension to global shocks is immediate; global shocks enter exactly as before into the investment equation and, as before, they do not enter into the current account equation. Note that the system of estimating equations is just identified. ${ }^{37}$

Table 8 presents joint estimates of eq. (26) and eq. (27) for each country (with global shocks included). ${ }^{38}$ The investment results are, of course, identical to those in Table 3 since the modified investment equation (26) is isomorphic to the earlier eq. (11). Note that our estimates of $\gamma_{2}^{\prime}$ (the coefficient on country-specific productivity in the $\Delta C A$ ecjuation) are

\footnotetext{
${ }^{37}$ The form in which we have written the current account and investment equation does not require any crossequation restrictions for identification. One could write the current account equation in terms of $\Delta A_{t}^{c}$ and $\epsilon_{t}\left(=A_{t}^{c}-\rho A_{t-1}^{c}\right)$ instead of in terms of $A_{t}^{c}$ and $A_{t-1}^{c}$ as we have done. In this case one would have to impose the constraint that the coefficient on $A_{t-1}^{c}$ is $\rho$ times the coefficient on $A_{t}^{c}$ to obtain identification. This equivalent approach (which yields identical estimates) is the conventional one. Note that there would be an overidentifying cross-equation restriction if the consumption equation (24) were estimated jointly with (26), (27), and (9).

${ }^{38}$ These joint estimates were obtained with the RATS SUR command. To adjust for cross-equation heteroscedascity, each equation was scaled by the standard error of the corresponding OLS regression.
} 
virtually identical to the estimates of $\gamma_{2}$ in Table 3 for the random walk case. (For the U.K., $\gamma_{2}^{\prime}$ is now marginally larger in absolute value than $\beta_{2}^{\prime}$, but in all other cases $\beta_{2}^{\prime}$ is larger.

Table 8 also presents chi-square tests of the restriction $\beta_{2}^{\prime}=\left|\gamma_{2}^{\prime}\right| ; \beta_{2}^{\prime}$ is significantly larger for all cases except the U.K. and the U.S. Thus, it appears that our empirical result that country-specific productivity shocks do not have a larger effect on the current account than on investment remains intact when one relaxes the $\rho=1$ assumption.

\section{B. The Sensitivity of $\left|\gamma_{2}^{\prime}\right| / \beta_{2}^{\prime}$ to $\rho$}

At first glance, it would seem that given the highly linear nature of the model, our estimated values of $\rho$ (which average .94 in Table 2) are simply too close to one to explain why, ernpirically, $\gamma_{2}^{\prime}$ appears to be less than half as large (on average) as $\beta_{2}^{\prime}$. It is well known from the consumption literature, however, that the response of variables which depend on present discounted calculations (as is the case here for both the current account and investment) can depend in a very nonlinear fashion on the persistence of the exogenous variables.

The fundamental intuition is most easily seen by abstracting from investment and assuming that net output $y$ is exogenous. In this case, eq. (24) for the innovation in consumption $(\tilde{C}=\Delta C)$ reduces to:

$$
\tilde{C}_{t}=\frac{r-1}{r-\rho} \alpha_{A} \epsilon_{t}
$$

If the gross real interest rate $r$ is a number like 1.03, then when $\rho$ falls from 1 to .97 , the consumption response halves (the denominator in eq. (28) goes from .03 to .06). At 
$\rho=.91$, the consumption response is $1 / 4$ as large. ${ }^{38}$ Endogenizing investment amplifies this difference (since the response of investment declines as $\rho$ falls). Because the consumption response to an income shock drops sharply as $\rho$ falls, the current account response is likely to be similarly muted. ${ }^{39}$

Consumption is not the whole story since the investment response to a procluctivity account shock is also muted by a fall in $\rho$. Therefore, the preceeding logic is not enough to show that

$$
\partial\left(\left|\gamma_{2}^{\prime}\right| / \beta_{2}^{\prime}\right) / \partial \rho<0
$$

We prove in Appendix 1, however, that (29) indeed holds, and that $\left|\gamma_{2}^{\prime}\right| / \beta_{2}^{\prime}$ is monotonically decreasing in $\rho$ for $\gamma_{2}^{\prime}<0,0<\rho<1$.

Can a very long-run convergence effect be large enough to explain the apparent anomaly in Tables 3 and 8? In Table 9, we calculate implied values of $\beta_{2}^{\prime}$ and $\gamma_{2}^{\prime}$ using estimates for the production function parameters in eqs. (3) and (4) based on Shapiro (1986). (The parameters are listed in the table.) The table gives the value of $\left|\gamma_{2}^{\prime}\right| / \beta_{2}^{\prime}$ corsesponding to different values of $\rho$. For $\rho=.97$, the implied values of $\beta_{2}^{\prime}=.32$ and $\gamma_{2}^{\prime}=-.21$ are very close to our pooled empirical estimates in Table 4. Thus the distinction between random walk and near random walk productivity may be central to explaining the small response of the current account.

\footnotetext{
${ }^{38}$ For discussion of income persistence and its implications for consumption volatility, see I)eaton (1992). Mankiw and Shapiro (1985) also stress the importance of stationarity in tests of the permanent income hypothesis.

${ }^{39}$ Of course, if one abstracts from investment, then productivity shocks always lead to a curren: account surplus with $\rho<1$.
} 


\section{Applying the Model to Explain the Reduced Form $\Delta C A-\Delta I$ Correlations}

Earlier in Table 1 we saw that there is a rather striking empirical regularity between changes in the current account and changes in investment. For the G-7 countries, the coefficient on $\Delta I$ in the $\Delta C A$ regressions averaged around $1 / 3$ (in absolute value). In this section we do some crude calculations to see if our simple intertemporal model based on productivity shocks is consistent with this regularity. For simplicity, it is helpful to focus on the random walk case $(\rho=1)$, and to further assume that $\beta_{1}=1$ (our point estimate in the pooled data in Table 4 was .90), and $\beta_{2}=\beta_{3}$ (i.e., that global and country-specific shocks affect irivestment equally). One then can easily solve for the slope coefficient in the regression of $\triangle C A$ on $\Delta I:^{40}$

$$
b=\frac{\gamma_{2}}{\beta_{2}}\left(\frac{\sigma_{\Delta A^{c}}^{2}}{\sigma_{\Delta A^{c}}^{2}+\sigma_{\Delta A^{*}}^{2}}\right)
$$

To implement (30), note that the pooled results in Table 4 provide an estimate of $\gamma_{2} / \beta_{2}$ roughly equal to -.48 . The ratio $\sigma_{\Delta A^{c}}^{2} /\left(\sigma_{\Delta A^{c}}^{2}+\sigma_{\Delta A^{*}}^{2}\right)$ is .49 in our sample when averaged over the seven countries. ${ }^{41}$ Combining these two parameters, one obtains an estimate of $b=-.24$. Thus, taking into account the fact that global shocks are roughly as important as local shocks -- and only investment responds to global shocks -- supplies half the explanation why the non-structural coefficients in Table 1 are closer to $-1 / 3$ than to -1 . The other half of the explanation lies in the estimate of $\left|\gamma_{2}\right| / \beta_{2}$, which instead of being greater than one is closer to $1 / 2$. As we have argued, this estimate is quite plausible provided country-specific

\footnotetext{
${ }^{40} \mathrm{We}$ have also assumed that $\Delta A^{c}$ is uncorrelated with $\Delta A^{w}$, which holds exactly for a small country.

${ }^{41}$ The ratio $\sigma_{\Delta A^{c}}^{2} /\left(\sigma_{\Delta A^{c}}^{2}+\sigma_{\Delta A}^{2}\right)$ is as follows for the countries in our sample: U.S., .32, Canada, .56; Japan, .70 ; France, .42; Germany, .37; Italy, .63; U.K., .41.
} 
productivity shocks are not literally a random walk, so that there is some degree of long-run convergence.

\section{Conclusions}

Earlier attempts at empirical implementation of the intertemporal model of the current account have been limited to simulation or vector autoregression methods. ${ }^{42}$ The present paper introduces a tractable approach to structural estimation. ${ }^{43}$ The ability to derive closed form solutions helps clarify some interesting issues that may easily be obscured in simulation analysis or vector autoregression estimation. With the source of results less of a block box this class of models potentially becomes more useful for policy analysis.

Overall, our empirical model performs fairly well in explaining the stable correlation between investment and the current account, in differences, over the period 1961-1990. Investment consistently responds positively and significantly to both country-speciric and global productivity shocks. The current account responds negatively and generally significantly to country-specific shocks; as the model predicts, there is little or no response to global shocks. The fact that investment responds by more than the current account to country-specific shocks would be a puzzle, if country-specific productivity shocks literally followed a random walk. But with even a small degree of mean reversion, the results can be fully explained. (Global shocks also tend to follow a near random walk, but since the

\footnotetext{
${ }^{42}$ Some examples of simulation studies include the open-economy real business cycles analyses of Backus, Kydland, and Kehoe (1992), Baxter and Cruccini (1992), Mendoza (1991), Stockman and Tesar (1990), and Tesar (1993). Ahmed, Ickes, Wang, and Yoo (1993) apply a variant of the Blanchard-Quah vector-autoregression methodology. It should be noted that in a world of complete goods and capital markets the current account and investment would move one for one in response to country-specific productivity shocks, regardless of their duration.

${ }^{43}$ An important exception is Ahmed (1986), who focuses on the effects of permanent versus transitory government spending shocks. Ahmed's model, however, does not incorporate investment or prodictivity shocks.
} 
current account impact is zero regardless, they do not present a similar puzzle.) Thus our empirical results may be construed as providing evidence that there is a significant convergent component to productivity across G-7 countries.

There are other possible explanations of the stylized fact we have established. Allowing for nontraded goods can reduce the relative response of the current account. ${ }^{44}$ Even with perfectly integrated international capital markets, moral hazard problems at the microeconomic level can force home residents to self-finance a larger portion of domestic investment than they would under perfect information. ${ }^{45}$ It would be interesting to explore these issues in future research; hopefully the tractable empirical model presented here will provide a useful benchmark against which these alternatives may be compared.

\footnotetext{
${ }^{44}$ Stockman and Tesar (1990) introduce non-traded goods into an open-economy real business cycle model; see also Baxter and Crucini (1992) and Tesar (1993).

${ }^{45}$ See Gertler and Rogoff (1990).
} 


\section{References}

Abel, Andrew and Olivier Blanchard, 1986, "The Present Value of Profits and Cyclical Movements in Investment," Econometrica 54 (March), 244-73.

Ahmed, Shaghil, 1986, "Temporary and Permanent Government Spending in an Open Economy: Some Evidence for the United Kingdom," Journal of Monetary Economics (March), 197-224.

Ahmed, Shaghil, Barry Ickes, Ping Wang, and Sam Yoo, 1993, "International Business Cycles," American Economic Review, forthcoming.

Backus, David, Patric Kehoe and Finn Kydland, 1992, "International Real Business Cycles," Journal of Political Economy 100 (August), 745-76.

Barro, Robert, 1986, "Government Spending, Interest Rates, Prices, and Budget Deficits in the United Kingdom," Journal of Monetary Economics (March), 221-47.

Barro, Robert and Xavier Sala-i-Martin, 1990, “World Real Interest Rates,” NBER Working Paper No. 3317.

Baxter, Marianne, and Mario J. Crucini, 1992, "Business Cycles and the Asset Structure of Foreign Trade," Federal Reserve Bank of Minneapolis, Institute for Empirical Macroeconomics Discussion Paper No. 59, March.

Blanchard, Olivier and Stanley Fischer, 1989, Lectures on Macroeconomics, Cambridge, MA: MIT Press.

Christiano, Lawrence J., 1992, "Searching for a Break in GNP," Journal of Business and Economic Statistics 10 (July).

Deaton, Angus, 1992, Understanding Consumption, Oxford: Oxford University Press.

Englander, Steven and Axel Mittelstädt, 1988, "Total Factor Productivity: Macroeconomic and Structural Aspects of the Slowdown," OECD Economic Studies 10, (Spring), 756.

Feldstein, Martin and Charles Horioka, 1980, "Domestic Savings and International Capital Flows,” Economic Journal 90, 314-29.

Frenkel, Jacob and Assaf Razin, 1987, Fiscal Policies and the World Economy, Cambridge, MA: MIT Press.

Gertler, Mark and Kenneth Rogoff, 1990, "North-South Lending and Endogenous Domestic Capital Market Inefficiencies," Journal of Monetary Economics 26 (October), 245-66. 
Glick, Reuven and Kenneth Rogoff, 1992, "Global versus Country-Specific Productivity Shocks and the Current Account," NBER Working Paper No. 4140.

Griliches, Zvi, 1988, “Productivity Puzzles and R\&D; Another Nonexplanation," Journal of Economic Perspectives 2 (Fall), 9-21.

Hall, Robert, 1978, "Stochastic Implications of the Life-Cycle Permanent Income Hypothesis: Theory and Evidence," Journal of Political Economy 86 (October), 97187.

Leiderman, Leonardo and Assaf Razin, 1991, "Determinants of External Imbalances: The Role of Taxes, Governmental Spending and Productivity," Journal of Japanese and International Economics 5, 421-50.

Levin, Andrew and Chen-Fu Lin, 1992, "Unit Root Tests in Panel Data: Asymptotic and Finite Sample Properties," University of California, San Diego, Department of Economics Discussion Paper 92-23.

Mankiw', N. Gregory and Matthew Shapiro, 1985, "Trends, Random Walks, and Tests of the Permanent Income Hypothesis," Journal of Monetary Economics 16, 165-74.

Meese, Richard, 1980, “Dynamic Factor Demand Schedules for Labor and Capital Under Rational Expectations," Journal of Econometrics 14 (September), 141-58.

Mendoza, Enrique G., 1991, "Real Business Cycles in the Small Open Economy," American Economic Review 81 (September), 797-818.

Meyer-zu-Schlochtern, F.J.M., 1988, “An International Sectoral Data Base for Thirteen OECD Countries," OECD Department of Economics and Statistics Working Paper No. 57.

Obstfeld, Maurice, 1986, "Capital Mobility and the World Economy: Theory and JMeasurement," Carnegie-Rochester Conference Series on Public Policy 24, 55-104.

Penati, Allessandro and Michael Dooley, 1984, Current Account Imbalances and Capital Formation in Industrial Countries, 1949-81, IMF Staff Papers 31 (March), 1-24.

Quah, Danny, 1990, “Permanent and Transitory Movements in Labor Income: An Explanation for 'Excess Smoothness' in Consumption," Journal of Political Economy 98 (June), 449-75.

Razin, Assaf, and Andrew Rose, 1992, "Business-Cycle Volatility and Openness: An Exploratory Cross-Section Analysis,” NBER Working Paper No. 4208. 
Roubini, Nouriel, 1988, "Current Account and Budget Deficits in an Intertemporal Model of Consumption and Taxation Smoothing. A Solution to the 'Feldstein-Horioka Puzzle?'” NBER Working Paper No. 2773.

Sachs, Jeffrey, 1981, "The Current Account and Macroeconomic Adjustment in the 1970s," Brookings Papers on Economic Activity 12, 201-68. , 1983, "Aspects of the Current Account Behavior of OECD Countries," in E. Classon and P. Salin (eds.), Recent Issues in the Theory of Flexible Exchange Rates, Amsterdam: North Holland

Shapiro, Matthew, 1986, "Investment, Output and the Cost of Capital," Brookings Papers on Economic Activity (No. 1), 111-52.

Stockman, Alan and Linda Tesar, 1990, "Tastes and Technology in a Two-Country Model of the Business Cycle: Explaining International Movements," NBER Working Paper No. 3566.

Tesar, Linda, 1991, “Savings, Investment, and International Capital Flows,” Journal of International Economics 31 (August), 55-78.

Tesar, Linda L., 1993, “International Risk-Sharing and Nontraded Goods,” Journal of International Economics, forthcoming. 


\section{Appendix 1}

A. Derivation of equations (14) and (24) for $\Delta \mathrm{C}$

Firom eq. (8),

$$
\Delta C_{t}=\bar{y}_{t}-E_{t-1} \bar{y}_{t}, \text { where } \bar{y}_{t}=\left(\frac{r-1}{r}\right) E_{t} \sum_{s=0}^{\infty} y_{t+s} / r^{s} .
$$

Denoting the revision of expectations operator $E_{t}-E_{t-1}$ as “ ", eq. (3) implies that $r /(r-1) \Delta \mathrm{C}$ equals

$$
\sum_{s=0}^{\infty} \tilde{y}_{t+s} / r^{s} \equiv \sum_{s=0}^{\infty}\left(\tilde{Y}_{t+s}-\tilde{I}_{t+s}\right) / r^{s}=\sum_{s=0}^{\infty}\left[\left(\alpha_{I}-1\right) \tilde{I}_{t+s}+\alpha_{A} \tilde{A}_{t+s}+\alpha_{K} \tilde{K}_{t+s}\right] / r^{s}
$$

(In this appendix, we omit " $c$ " superscripts on the $A$ shocks for notational convenience.)

When $\rho=1$, note that by eqs. (9) and (10)

$$
\tilde{A}_{t+s}=\Delta A_{t}, \quad \forall s
$$

and

$$
\tilde{I}_{t+s}=\beta_{2} \beta_{1}^{s} \Delta A_{t}, \quad \forall s
$$

By eqs. (2), (A2), and (A3),

$$
\tilde{K}_{t+s}=\sum_{i=0}^{s} \tilde{I}_{t+i-1}=\left(\beta_{2} / \beta_{1}\right) \Delta A_{t}\left[\left(\sum_{i=0}^{s} \beta_{1}^{i}\right]-1\right]
$$

Eqs. (A2) - (A4) imply

$$
\begin{gathered}
\sum_{s=0}^{\infty} \tilde{A}_{t+s} / r^{s}=\frac{r}{r-1} \Delta A_{t} \\
\sum_{s=0}^{\infty} \tilde{I}_{t+s} / r^{s}=\beta_{2}\left(\frac{r}{r-\beta_{1}}\right) \Delta A_{t} \\
\sum_{s=0}^{\infty} \tilde{K}_{t+s} / r^{s}=\sum_{s=0}^{\infty} \sum_{i=0}^{s} \tilde{I}_{t+i-1} / r^{s}=\beta_{2}\left(\frac{r}{r-\beta_{1}}\right)\left(\frac{1}{r-1}\right) \Delta A_{t}
\end{gathered}
$$

Substituting (A5) - (A7) into (A1) gives the reduced-form expression (14) for $\Delta C_{t}$. 
When $\rho<1$, eqs. (4) and (9) imply

$$
\begin{aligned}
I_{t} & =\beta_{1} I_{t-1}+\eta \sum_{i=1}^{\infty}(\lambda \rho)^{i} \Delta A_{t} \\
& =\beta_{1} I_{t-1}+\beta_{2}^{\prime} \Delta A_{t}
\end{aligned}
$$

where $\beta_{2}^{\prime} \equiv \eta \lambda \rho /(1-\lambda \rho)$. Derivation of equation (22) for $\tilde{I}_{t}$ and and (26) for $\Delta I_{t}$ is immediate.

It follows from (9) and (A8) that

$$
\tilde{A}_{t+s}=\rho^{s} \tilde{A}_{t}, \quad \forall s
$$

and

$$
\tilde{I}_{t+s}=\beta_{2}^{\prime} \sum_{j=0}^{s} \beta_{1}^{j} \Delta \tilde{A}_{t+s-j}, \quad \forall s
$$

where again by (9)

$$
\Delta \tilde{A}_{t+s}= \begin{cases}\epsilon_{t} & \text { for } s=0 \\ \rho^{s-1}(\rho-1) \epsilon_{t} & \text { for } s>1\end{cases}
$$

By eqs. (2), (A10) and (A11)

$$
\tilde{K}_{t+s}=\sum_{i=0}^{s} \tilde{I}_{t+i-1}=\beta_{2}^{\prime} \sum_{i=0}^{s} \sum_{j=0}^{i} \beta_{1}^{j} \Delta \tilde{A}_{t+i-1-j}
$$

Eqs. (A9) - (A12) imply

$$
\begin{gathered}
\sum_{s=0}^{\infty} \tilde{A}_{t+s} / r^{s}=\sum_{s=0}^{\infty} \rho^{s} \epsilon_{t} / r^{s}=\frac{r}{r-\rho} \epsilon_{t} \\
\sum_{s=0}^{\infty} \tilde{I}_{t+s} / r^{s}=\beta_{2}^{\prime} \sum_{s=0}^{\infty} \sum_{j=0}^{s} \beta_{1}^{j} \Delta \tilde{A}_{t+s-j} / r^{s}=\beta_{2}^{\prime}\left[\frac{r}{r-\beta_{1}}\right]\left[1+\frac{\rho-1}{r-\rho}\right] \epsilon_{t} \\
\sum_{s=0}^{\infty} \tilde{K}_{t+s} / r^{s}=\beta_{2}^{\prime} \sum_{s=0}^{\infty} \sum_{i=0}^{s} \sum_{j=0}^{i} \beta_{1}^{j} \Delta \tilde{A}_{t+i-1-j} / r^{s}=\beta_{2}^{\prime}\left[\frac{r}{r-\beta_{1}}\right]\left[\frac{1}{r-1}\right]\left[1+\frac{\rho-1}{r-\rho}\right] \epsilon_{t}
\end{gathered}
$$

Substituting (A13) - (A15) into (A1) gives the reduced-form expression (24) for $\Delta C_{t}=\tilde{C}$. 


\section{B. Derivation of Equation (27) for $\triangle C A$}

To derive expression (27) for $\Delta C A$ note that

$$
\begin{aligned}
\Delta C A & =\tilde{C A_{t}}+E_{t-1} C A_{t}-C A_{t-1} \\
& =\tilde{C A_{t}}+E_{t-1}\left(Y_{t}-I_{t}-C_{t}\right)-Y_{t-1}-I_{t-1}-C_{t-1}+(r-1) C A_{t-1}
\end{aligned}
$$

From (25)

$$
\tilde{C A_{t}}=\gamma_{2}^{\prime} \epsilon_{t}
$$

From (A8) and (9)

$$
E_{t-1} I_{t}-I_{t-1}=\beta_{1} I_{t-1}+\beta_{2}^{\prime}(\rho-1) A_{t-1}-I_{t-1}
$$

Using eqs. (3) and (B3)

$$
\begin{aligned}
E_{t-1} Y_{t}-Y_{t-1} & =E_{t-1}\left[\alpha_{I} I_{t}+\alpha_{A} A_{t}+\alpha_{K} K_{t}\right]-\left[\alpha_{I} I_{t-1}+\alpha_{A} A_{t-1}+\alpha_{K} K_{t-1}\right] \\
& =\alpha_{\lambda}\left(E_{t-1} I_{t}-I_{t-1}\right)+\alpha_{A}\left(E_{t-1} A_{t}-A_{t-1}\right)+\alpha_{K}\left(E_{t-1} K_{t}-K_{t-1}\right) \\
& =\left(\alpha_{t} \beta_{2}^{\prime}+\alpha_{A}\right)(\rho-1) A_{t-1}+\left[\alpha_{t}\left(\beta_{1}-1\right)+\alpha_{K}\right] I_{t-1}
\end{aligned}
$$

where we have used the fact that $E_{t-1} A_{t}-A_{t-1}=(\rho-1) A_{t-1}$ and $E_{t-1} K_{t}-K_{t-1}=I_{t-1}$. Since $E_{t-1} C_{t}-C_{t-1}=0$, substitution of (B2) - (B4) in (B1) yields eqn. (27).

C. Proof that $\partial\left(\left|\gamma_{2}^{\prime}\right| / \beta_{2}^{\prime}\right) / \partial \rho>0$.

$$
\text { To evaluate } \frac{\partial\left|\gamma_{2}^{\prime}\right| / \beta_{2}^{\prime}}{\partial \rho} \text {, we first evaluate } \partial \beta_{2}^{\prime} / \partial \rho \text { and } \partial\left|\gamma_{2}^{\prime}\right| / \partial \rho \text {. }
$$

From the definitions of $\beta_{2}^{\prime}$ and $\gamma_{2}^{\prime}$

$$
\begin{gathered}
\frac{\partial \beta_{2}^{\prime}}{\partial \rho}=\frac{\eta \lambda}{(1-\rho \lambda)^{2}}>0 \\
\frac{\partial\left|\gamma_{2}^{\prime}\right|}{\partial \rho}=-\alpha_{A} \frac{1-r}{(r-\rho)^{2}}-\frac{\partial \beta_{2}^{\prime}}{\partial \rho}\left[\alpha_{1}-1-\frac{\phi(r-1)}{(r-\rho)\left(r-\beta_{1}\right)}\right]+\frac{\beta_{2}^{\prime} \phi(r-1)}{(r-\rho)^{2}\left(r-\beta_{1}\right)}>0
\end{gathered}
$$


since $\phi \equiv\left(\alpha_{I}-1\right)(r-1)+\alpha_{K}>0$. [In (C2), we evaluate in the region $\gamma_{2}^{\prime}<0$.] Differentiating $\left|\gamma_{2}^{\prime}\right| / \beta_{2}^{\prime}$ with respect to $\rho$ gives

$$
\frac{\partial\left|\gamma_{2}^{\prime}\right| / \beta_{2}^{\prime}}{\partial \rho}=\frac{1}{\left(\beta_{2}^{\prime}\right)^{2}}\left[\beta_{2}^{\prime} \frac{\partial\left|\gamma_{2}^{\prime}\right|}{\partial \rho}-\left|\gamma_{2}^{\prime}\right| \frac{\partial \beta_{2}^{\prime}}{\partial \rho}\right]
$$

Substituting for $\left|\gamma_{2}^{\prime}\right|$ with (25) and for $\partial\left|\gamma_{2}^{\prime}\right| / \partial \rho$ with (C2) yields

$$
\frac{\partial\left|\gamma_{2}^{\prime}\right| / \beta_{2}^{\prime}}{\partial \rho}=\frac{1}{\left(\beta_{2}^{\prime}\right)^{2}}\left[\beta_{2}^{\prime} \frac{\alpha_{A}(r-1)}{(r-\rho)^{2}}+\frac{\beta_{2}^{\prime} \phi(r-1)}{\left(r-\beta_{1}\right)(r-\rho)^{2}}+\alpha_{A} \frac{(1-\rho)}{r-\rho} \frac{\partial \beta_{2}^{\prime}}{\partial \rho}\right]>0
$$




\section{Appendix 2 Data}

Annual data for the years 1960-1990 for the current accounts of the balance of payments were obtained from International Financial Statistics (IFS), line 77a.d. Because the current accounts were expressed in dollars, they were converted to local currencies using the average market exchange rates for the year (rf). Data on France's current account is available only from 1967 , because of the absence of data on the transactions between metropolitan France and countries in the franc area in prior years.

Annual data on nominal investment, output, consumption, and government spending were obtained from the national accounts section of the IFS for each country. Investment was defined as the sum of gross fixed capital formation (line 93e) and changes in (inventory) stocks (line 93i). For the United States the investment total included government gross fixed capital formation (line $93 \mathrm{gf}$ ). Government spending was defined as government consumption (line 91f, or 91ff less 93gf in the case of the U.S.). Output was defined as GDP (line 99b) or when not available by GNP (line 99a).

All nominal aggregates were converted into real terms by the GDP or, where necessary, by the GNP deflator. The deflator was calculated as the ratio of real GDP (line 99b.r or 99b.p) or GNP (99a.r) to the corresponding nominal output aggregate.

To construct productivity, we used Bureau of Labor Statistics figures on manufacturing output and employment hours, as reported in "International Comparisons of Manufacturing Productivity and Unit Labor Costs, 1990," Table 2 (BLS, U.S. Department of Labor, 91-406). We formed our basic measure of total factor productivity as the Solow 
residuals from Cobb Douglas production functions, as described in the text, using the BLS data on manufacturing output and hours and the labor share figures of Stockman and Tesar (1990), and treating capital as following a constant trend.

An alternative measure of total factor productivity in manufacturing for the years 1970-1985 controlling for capital inputs was constructed using data on output, employment, and the capital stock from the OECD international sectoral data base and the Stockman and Tesar labor share figures. 
Table 1

Time-Series Regressions of Current Account on Investment $\Delta C A_{t}=a+b \Delta I_{t}$

\begin{tabular}{|c|c|c|c|c|}
\hline Country & $\begin{array}{l}\text { Sample } \\
\text { Period } \\
\end{array}$ & $b$ & $\mathbf{R}^{2}$ & D.W. \\
\hline U.S. & $1961-90$ & $-0.16(.07)^{* *}$ & .18 & 1.44 \\
\hline Japan & $1961-90$ & $-0.32(.07)^{* *}$ & .40 & 1.27 \\
\hline Germany & $1961-90$ & $-0.29(.11)^{* *}$ & .21 & 1.94 \\
\hline France & $1968-90$ & $-0.37(.11)^{* *}$ & .34 & 1.82 \\
\hline Italy & $1961-90$ & $-0.55(.08)^{* *}$ & .61 & 1.95 \\
\hline U.K. & $1961-90$ & $-0.53(.09)^{* *}$ & .53 & 2.08 \\
\hline Canada & $1961-90$ & $-0.31(.08)^{* *}$ & .37 & 2.06 \\
\hline U.S. & $1961-74$ & $0.04(.10)$ & .01 & 2.67 \\
\hline Japan & $1961-74$ & $-0.21(.11)^{*}$ & .24 & .89 \\
\hline Gerrnany & $1961-74$ & $-0.35(.09)^{* *}$ & .58 & 2.22 \\
\hline France & $1968-74$ & $0.10(.51)$ & .01 & 1.74 \\
\hline Italy & $1961-74$ & $-0.50(.16)^{* *}$ & .44 & 2.54 \\
\hline U.K. & $1961-74$ & $-0.37(.20)^{*}$ & .22 & 1.39 \\
\hline Canada & $1961-74$ & $-0.40(.11)^{* *}$ & .52 & 3.04 \\
\hline U.S & $1975-90$ & $-0.20(.09)^{* *}$ & .27 & 1.18 \\
\hline Japan & $1975-90$ & $-0.37(.10)^{* *}$ & .49 & 1.54 \\
\hline Germany & $1975-90$ & $-0.23(.19)$ & .10 & 1.60 \\
\hline France & $1975-90$ & $-0.42(.12)^{* *}$ & .47 & 1.42 \\
\hline Italy & $1975-90$ & $-0.59(.10)^{* *}$ & .71 & 1.19 \\
\hline U.K. & $1975-90$ & $-0.60(.10)^{* *}$ & .72 & 1.81 \\
\hline Canada & $1975-90$ & $-0.30(.10)^{* *}$ & .38 & 1.88 \\
\hline
\end{tabular}

Note: Figures in parentheses are standard errors. Significance levels at 5 and 10 percent indicated by $* *$ and $*$, respectively. 
Table 2

Country-Specific and Global Productivity Unit Root Tests, 1961-90

\begin{tabular}{|c|c|c|c|}
\hline Country & DF $t_{\tau}$ & $\operatorname{ADF} t_{\tau}$ & $\rho$ \\
\hline U.S. & -0.40 & -0.78 & $.93(.026)$ \\
\hline Japan & -1.14 & -0.87 & $.94(.020)$ \\
\hline Germany & -1.09 & -1.64 & $.98(.078)$ \\
\hline France & -0.52 & -0.86 & $.91(.048)$ \\
\hline Italy & -1.76 & -1.58 & $.95(.042)$ \\
\hline U.K. & -1.29 & -1.51 & $.89(.031)$ \\
\hline Canada & -2.43 & -1.76 & $1.01(.082)$ \\
\hline Global & -2.06 & -2.37 & $.97(.012)$ \\
\hline
\end{tabular}

Note: DF $t_{\tau}$ is the $t$-statistic on $b_{1}$ in the regression $\Delta A_{t}=b_{0}+b_{1} A_{t-1}$ $+b_{2} T$. ADF $t_{\tau}$ is the $t$-statistic on $b_{1}$ in the augmented regression $\Delta A_{t}=b_{0}+b_{1} A_{t-1}+b_{2} T+b_{3} \Delta A_{t-1}$. Critical values for $t_{\tau}$ (with 25 observations) are -3.60 at 5 percent and -3.24 at 10 percent. $\rho$ is the coefficient on $A_{t-1}$ in the regression $A_{t}=\alpha+\rho A_{t-1}$ with the standard error in parentheses. 


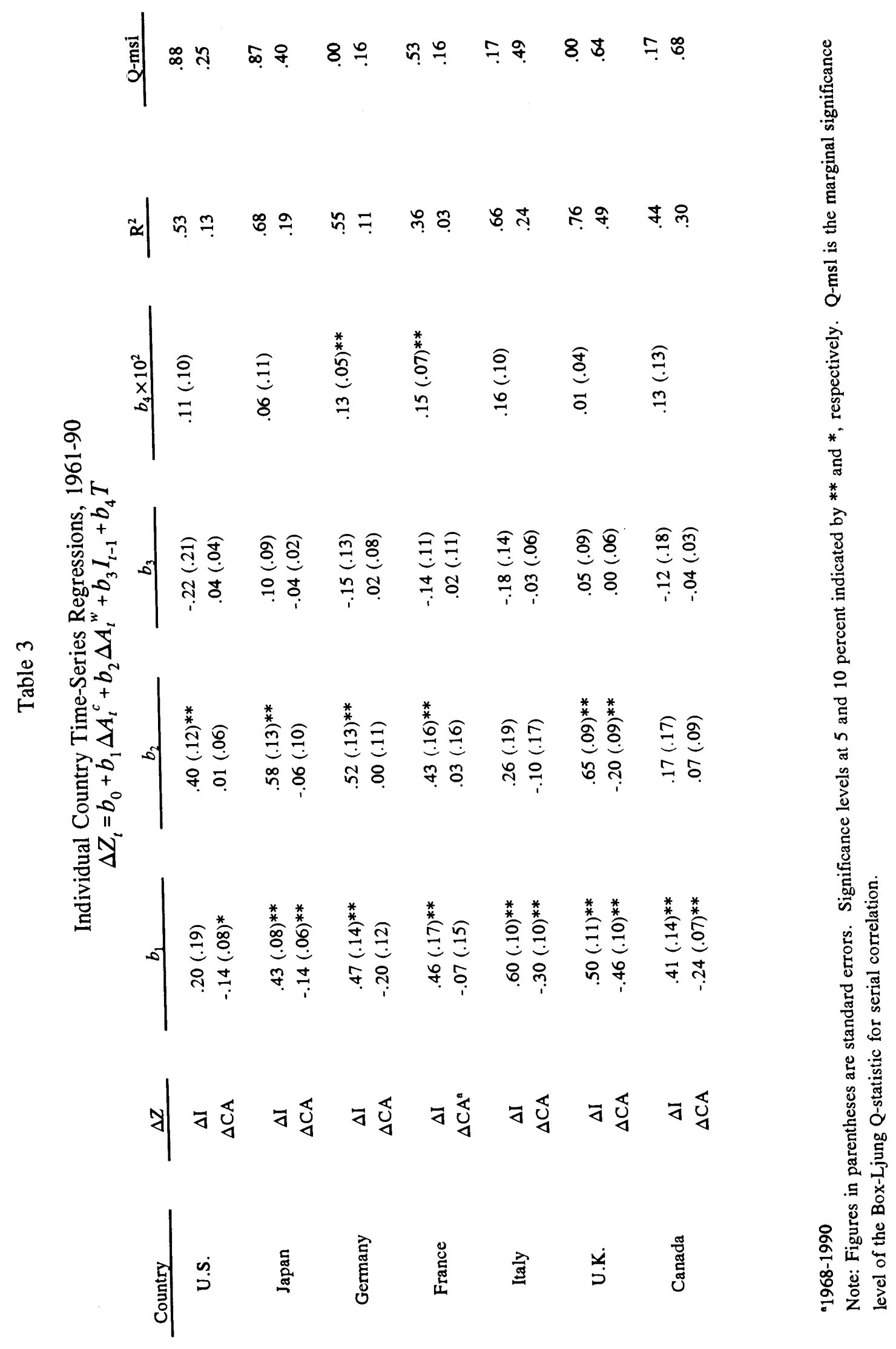

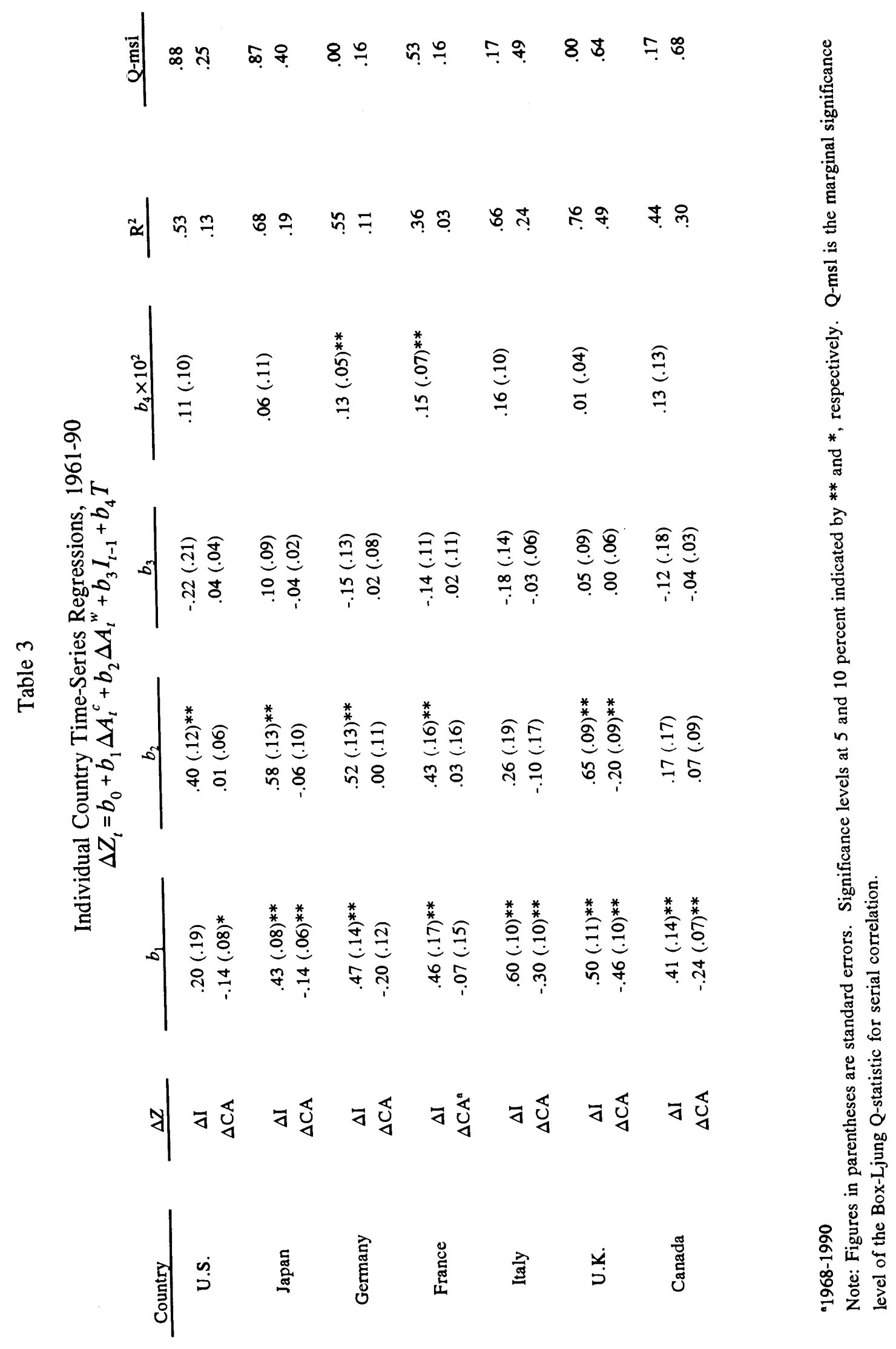

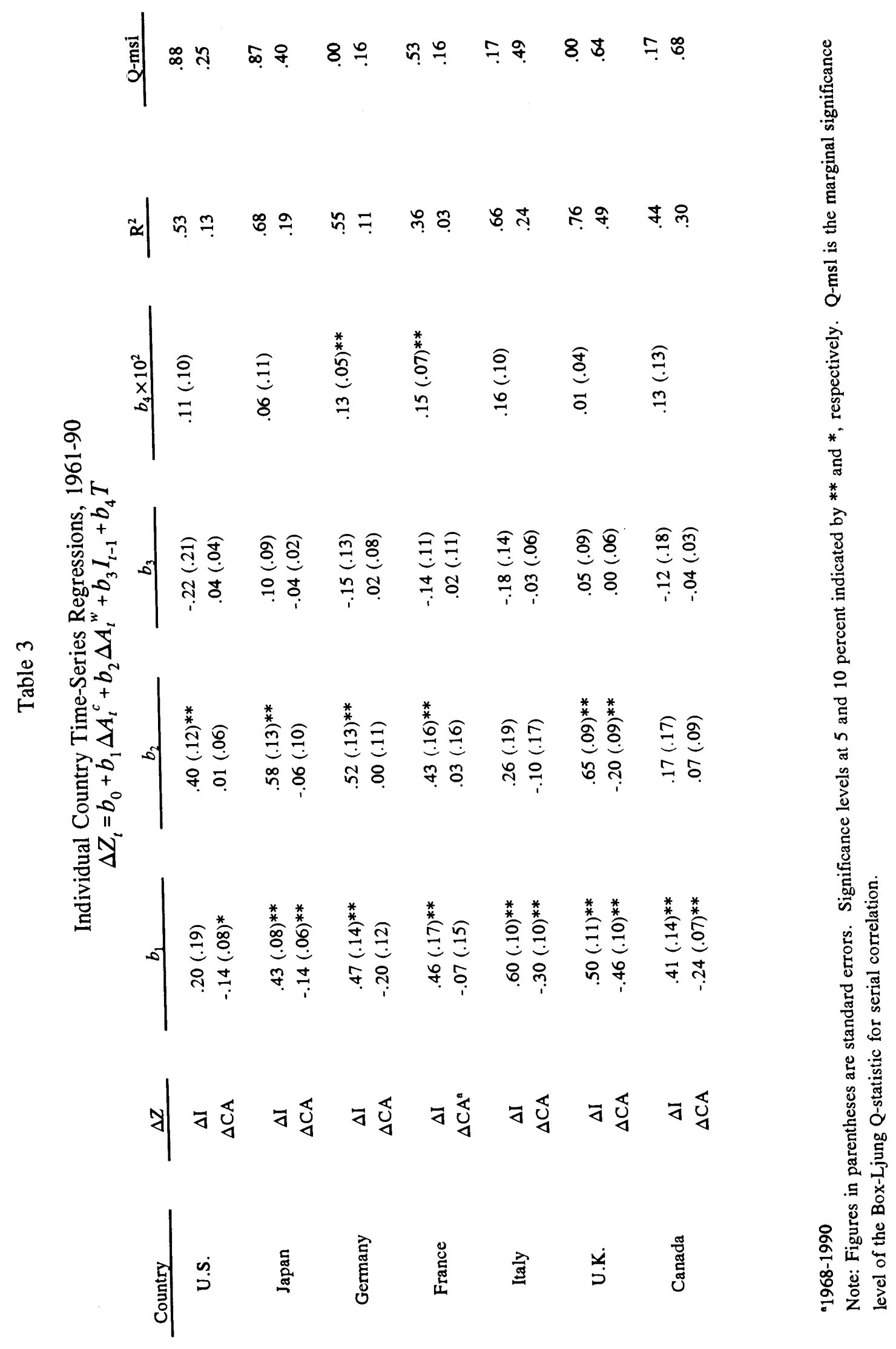


$\stackrel{\dot{\sim}}{\underset{\gamma}{*}}$

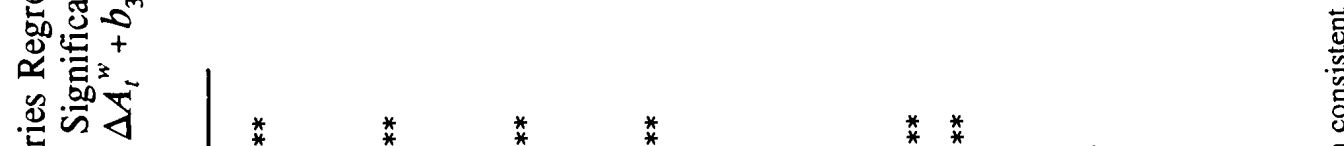

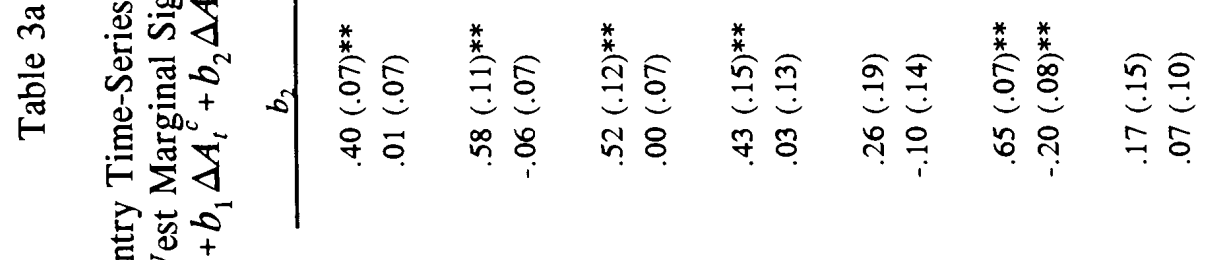

$$
\begin{aligned}
& \text { 寻 }
\end{aligned}
$$

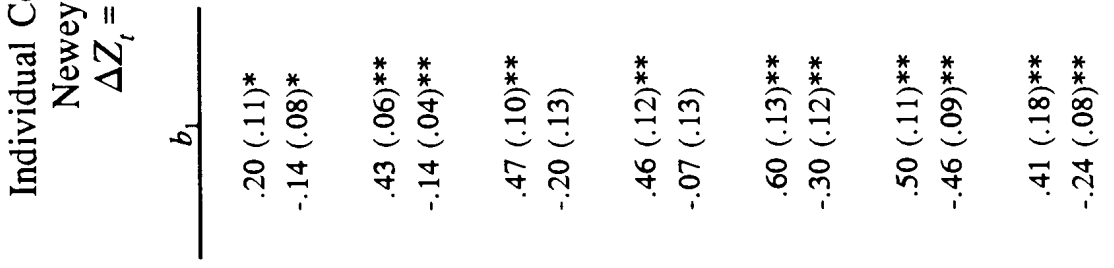

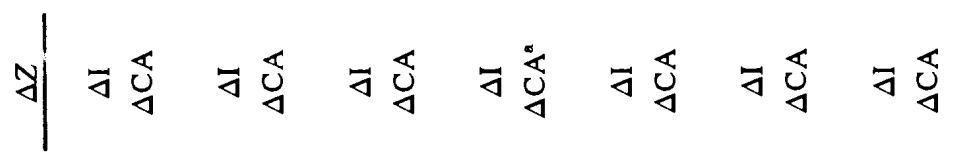

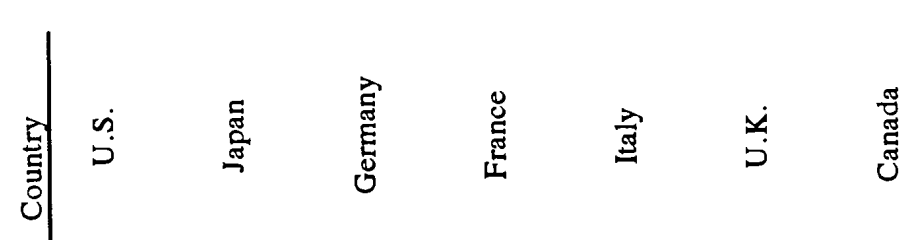

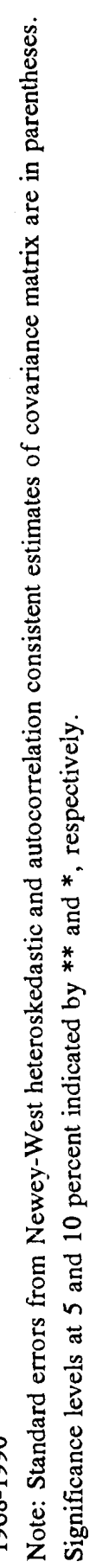


Table 4

Pooled Time-Series Regressions, 1961-90

$\Delta Z_{t}=b_{0}+b_{1} \Delta A_{t}{ }^{c}+b_{2} \Delta A_{t}{ }^{w}+b_{3} I_{t-1}+b_{4} T$

With Country-Specific Time Trends

\begin{tabular}{|c|c|c|c|}
\hline$\Delta Z$ & $b_{1}$ & $b_{2}$ & $b_{3}$ \\
\hline$\Delta \mathbf{I}$ & $.35(.03)^{* *}$ & $.53(.06)^{* *}$ & $-.10(.04)^{* *}$ \\
\hline$\Delta \mathrm{CA}$ & $-.17(.03)^{* *}$ & $.01(.02)$ & $.04(.03)$ \\
\hline \multicolumn{4}{|c|}{ Without Time Trends $\left(b_{4}=0\right)$} \\
\hline$\Delta \mathrm{I}$ & $.36(.03)^{* *}$ & $.56(.05)^{* *}$ & $.08(.02)^{* *}$ \\
\hline$\Delta \mathrm{CA}$ & $-.16(.02)^{* *}$ & $-.01(.02)$ & $-.01(.01)^{*}$ \\
\hline
\end{tabular}

Note: France excluded from $\triangle C A$ regressions. Figures in parentheses are standard errors. Significance levels at 5 and 10 percent indicated by ${ }^{* *}$ and $*$, respectively. 
Table 5

Pooled Time-Series Regressions, 1961-90, with Government Consumption

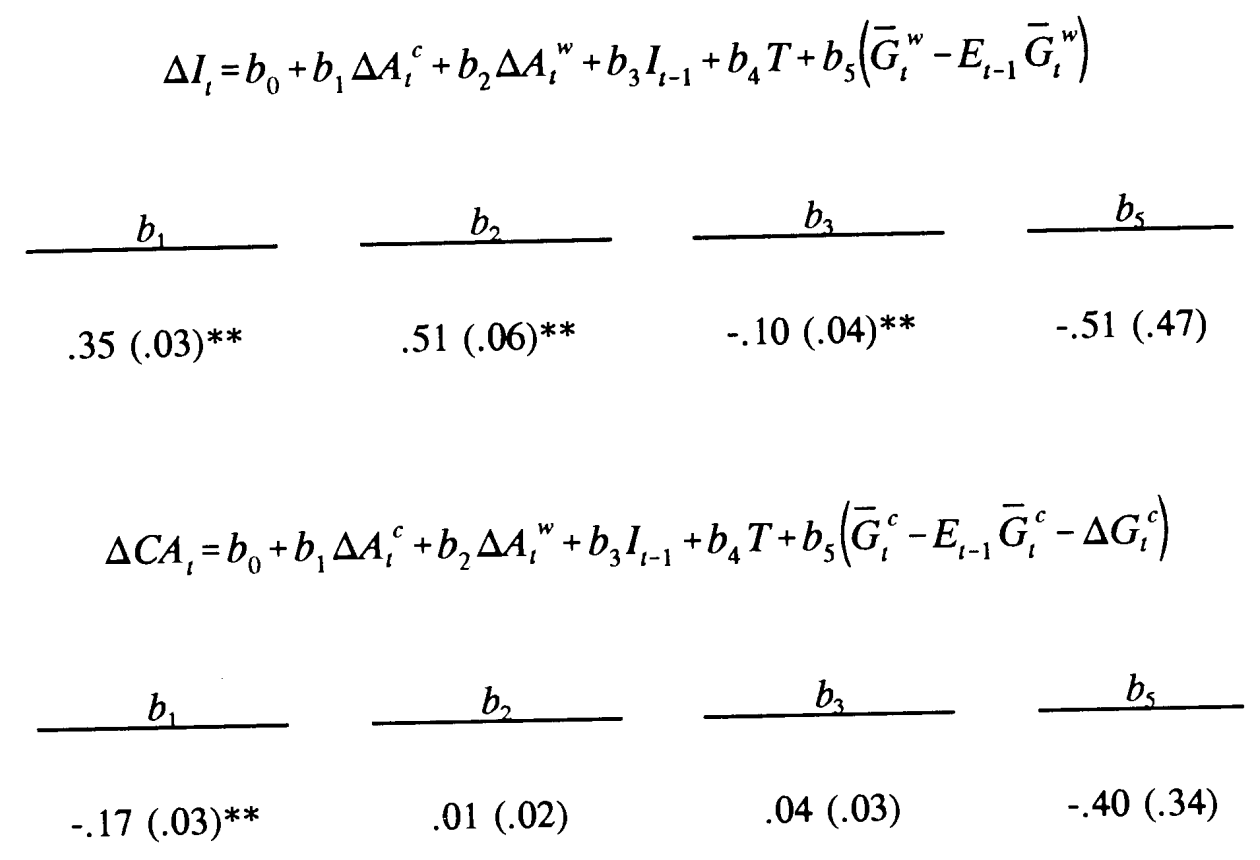

Note: Country-specific time trends not reported. France excluded from $\triangle C A$ regression. Figures in parentheses are standard errors. Significance levels at 5 and 10 percent indicated by ** and *, respectively. 
Table 6

Pooled Time-Series Regressions using OECD Total Factor Productivity Data, 1971-85 Subsample

$$
\Delta Z_{t}=b_{0}+b_{1} \Delta A_{t}^{c}+b_{2} \Delta A_{t}{ }^{w}+b_{3} I_{t-1}+b_{4} T
$$

With Country-Specific Time Trends

\begin{tabular}{|c|c|c|c|}
\hline$\Delta Z$ & $b_{1}$ & $b_{2}$ & $b_{3}$ \\
\hline$\Delta \mathrm{I}$ & $.36(.03)^{* *}$ & $.43(.06)^{* *}$ & $-.06(.07)$ \\
\hline$\Delta \mathrm{CA}$ & $-.27(.02)^{* *}$ & $.05(.02)^{* *}$ & $.05(.03)$ \\
\hline \multicolumn{4}{|c|}{ Without Time Trends $\left(b_{4}=0\right)$} \\
\hline$\Delta \mathbf{I}$ & $.39(.03)^{* *}$ & $.44(.06)^{* *}$ & $-.02(.05)$ \\
\hline$\Delta \mathrm{CA}$ & $-.28(.02)^{* *}$ & $.03(.01)$ & $-.01(.01)$ \\
\hline
\end{tabular}

Note: France excluded from $\triangle \mathrm{CA}$ regressions. Figures in parentheses are standard errors. Significance levels at 5 and 10 percent indicated by ${ }^{* *}$ and $*$, respectively. 
Table 7

Pooled Time-Series Regressions, 1975-90 Subsample $\Delta Z_{t}=b_{0}+b_{1} \Delta A_{t}^{c}+b_{2} \Delta A_{t}{ }^{w}+b_{3} I_{t-1}+b_{4} T$

With Country-Specific Time Trends

\begin{tabular}{|c|c|c|c|}
\hline$\Delta Z$ & $b_{1}$ & $b_{2}$ & $b_{3}$ \\
\hline$\Delta \mathbf{I}$ & $.34(.04)^{* *}$ & $.66(.06)^{* *}$ & $-.05(.05)$ \\
\hline$\Delta \mathrm{CA}$ & $-.30(.02)^{* *}$ & $.02(.02)$ & $.02(.03)$ \\
\hline \multicolumn{4}{|c|}{ Without Time Trends $\left(b_{4}=0\right)$} \\
\hline$\Delta \mathrm{I}$ & $.32(.03)^{* *}$ & $.62(.06)^{* *}$ & $.00(.04)$ \\
\hline$\Delta \mathrm{CA}$ & $-.26(.03)^{* *}$ & $-.01(.02)$ & $-.02(.02)$ \\
\hline
\end{tabular}

Note: France excluded from $\triangle \mathrm{CA}$ regressions. Figures in parentheses are standard errors. Significance levels at 5 and 10 percent indicated by ${ }^{* *}$ and $*$, respectively. 


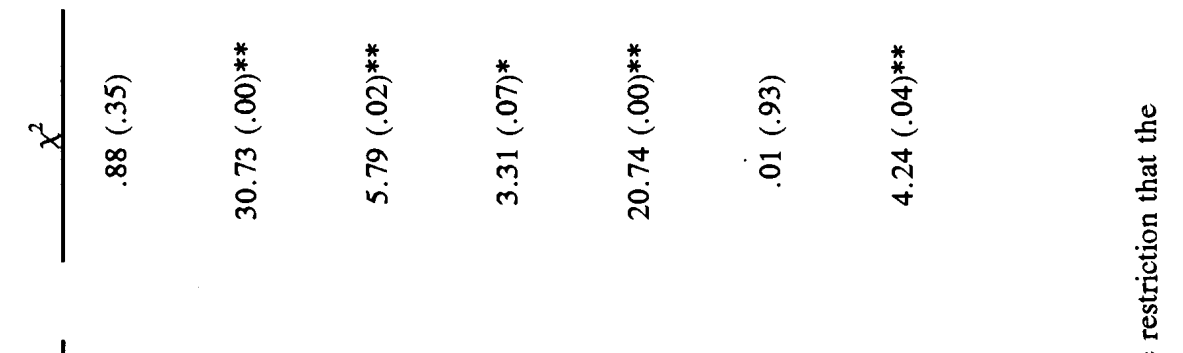

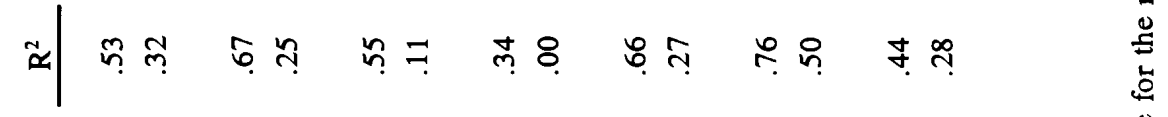

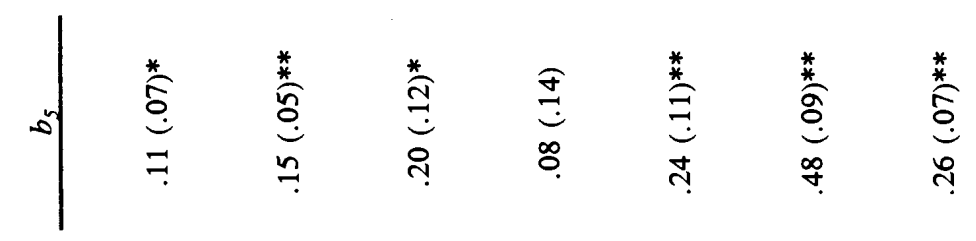

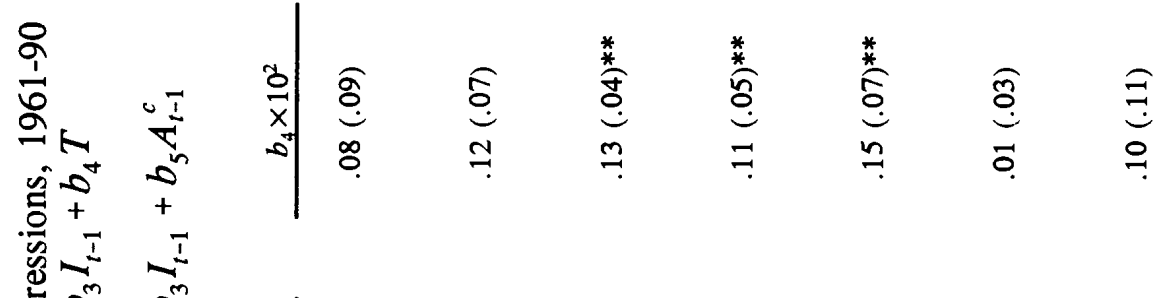

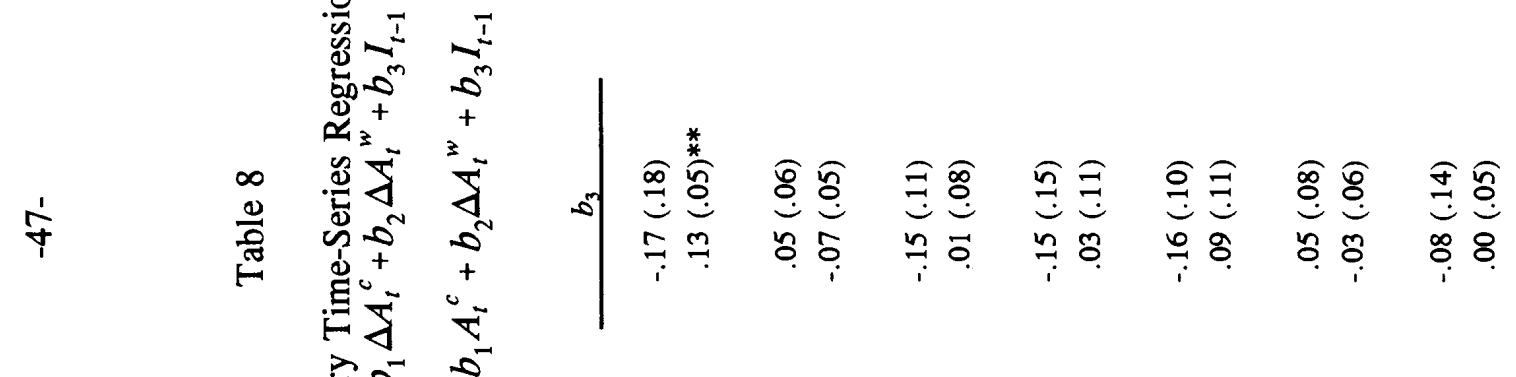

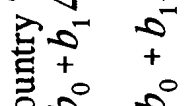

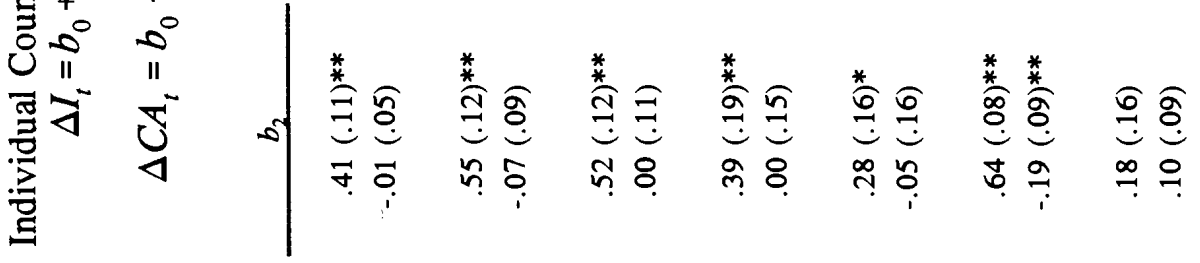

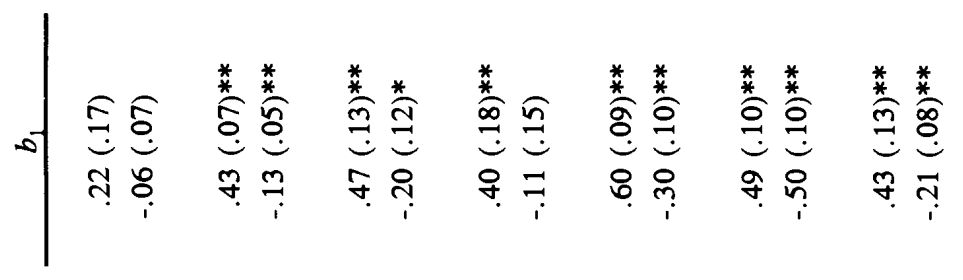

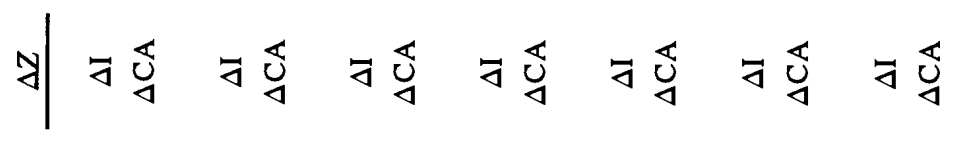

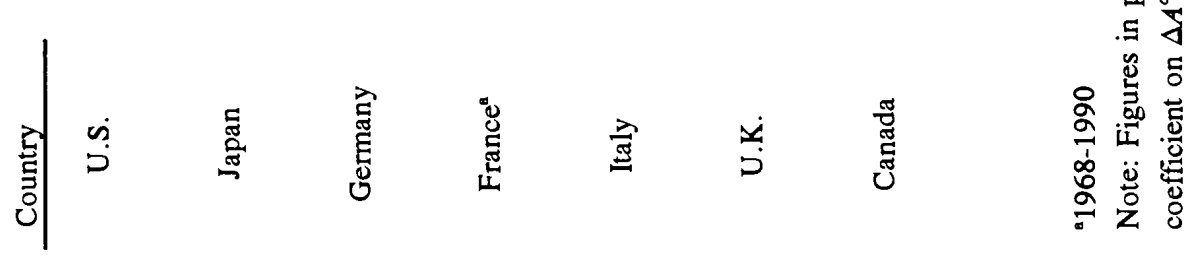


Table 9

Relative Response of Investment and the Current Account to Productivity Shocks as a Function of $\rho$

$$
\begin{gathered}
\tilde{I}=B_{2}^{\prime} \epsilon_{\epsilon} \\
\tilde{C A}=\tilde{\gamma}_{2} \epsilon_{\epsilon} \\
\beta_{2}^{\prime} \equiv \frac{\eta \lambda \rho}{1-\lambda \rho} \\
\gamma_{2}^{\prime} \equiv \alpha_{1} \frac{1-\rho}{r-\rho}+\beta_{2}^{\prime}\left(\alpha_{I}-1\right)-\frac{r-1}{r-\rho} \beta_{2}^{\prime} \frac{\left(\alpha_{I}-1\right)(r-1)+\alpha_{K}}{r-\beta_{1}}
\end{gathered}
$$

$\begin{array}{ccccc}\rho & \beta_{2}^{\prime} & & \gamma_{2}^{\prime} & \\ 1.00 & .35 & & -.97 & 2.76 \\ .99 & .35 & -.60 & 1.72 \\ .98 & .34 & -.35 & 1.04 \\ .97 & .32 & -.21 & 0.64 \\ .96 & .31 & -.04 & 0.13 \\ .95 & .30 & .05 & 0.18\end{array}$

Parameter Values:

$$
\begin{aligned}
\alpha_{I} & =-.39 \\
\alpha_{R} & =.22 \\
\alpha_{A} & =1.00 \\
\lambda & =.72 \\
\beta_{1} & =.90 \\
\eta & =.14 \\
r & =1.03
\end{aligned}
$$

Note: Authors calculations based on Shapiro (1986) values for $\alpha_{l}, \alpha_{K}$, $\alpha_{A}$, and $\lambda$. Since Shapiro's estimates were based on quarterly rates, annualized values were obtained by multiplying his value of $\alpha_{K}$ by 4 and by taking the fourth power of his estimate of $\lambda$. $\eta$ was calibrated by equating the formula for $\beta_{2}^{\prime}$ to .35 , the point estimate from the pooled regression in Table 4 , and assuming $\rho=1$ and $\lambda=.72 . \beta_{1}$ is taken from the pooled investment regression with country-specific time trends in Table 4. 


\section{Figure 1}

Total Factor Productivity in Manufacturing

(log changes)
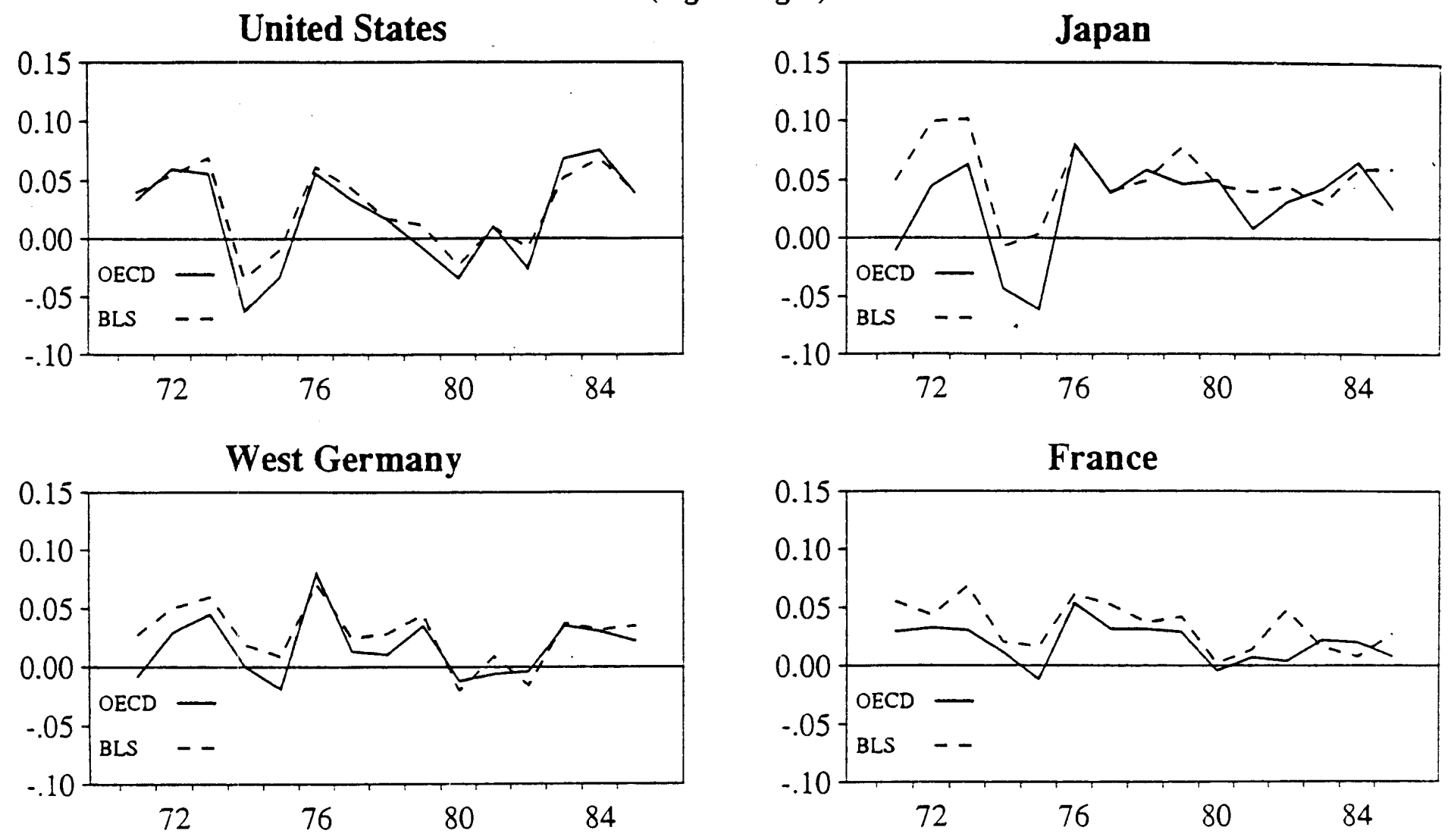

Italy

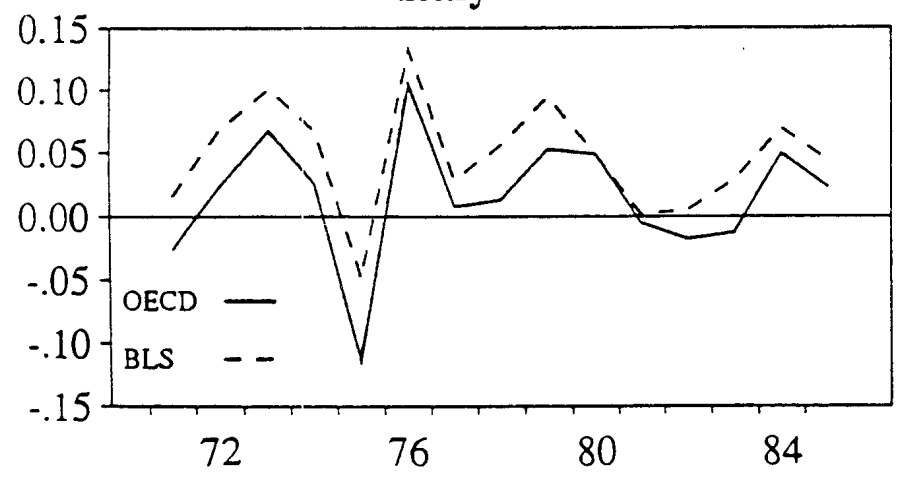

United Kingdom

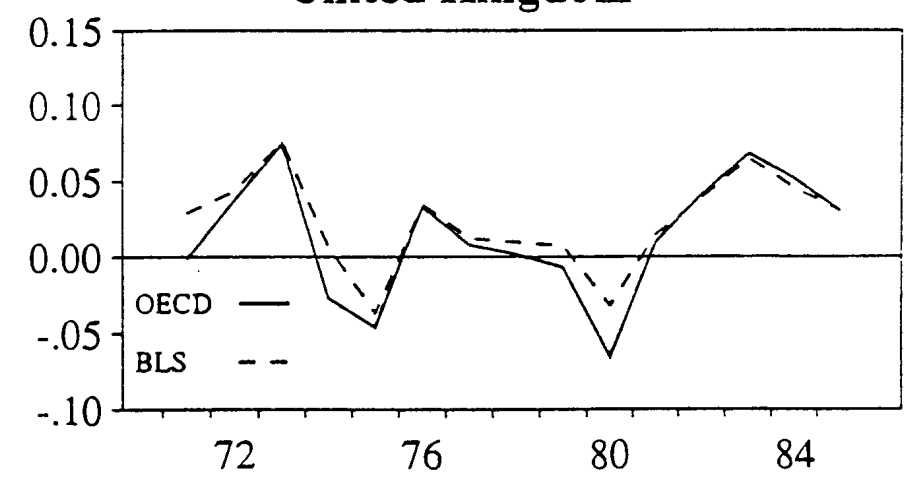

Canada

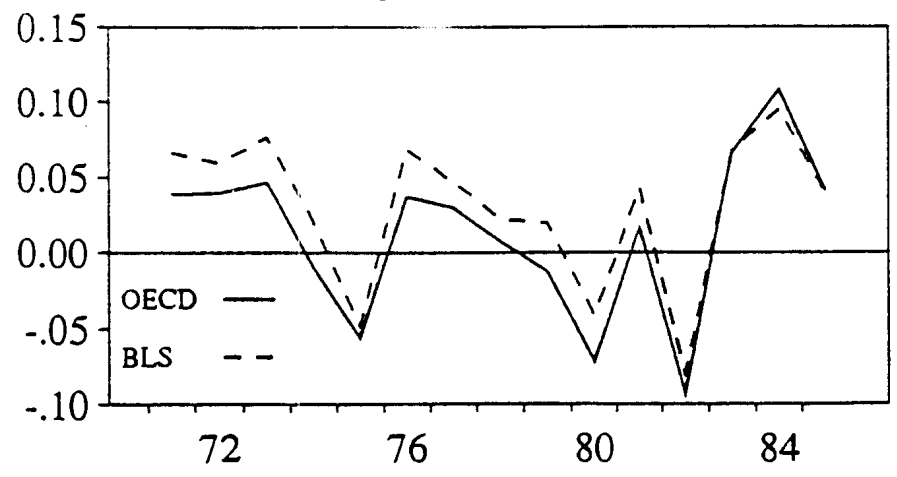

Note: See text for construction of Bureau of Labor Statistics and OECD measures of total factor productivity in manufacturing. 
IFDP

NUMBER

443

442

441

440

438

437

436

435

434

433

431
International Finance Discussion Papers

\section{TITLES}

$\underline{1993}$

Global versus Country-Specific Productivity Shocks and the Current Account

The GATT's Contribution to Economic Recovery in Post-War Western Europe

A Utility Based Comparison of Some Models of Exchange Rate Volatility

Cointegration Tests in the Presence of Structural Breaks

$\underline{1992}$

Life Expectancy of International Cartels: An Empirical Analysis

Daily Bundesbank and Federal Reserve Intervention and the Conditional

Variance Tale in DM/\$-Returns

War and Peace: Recovering the Market's Probability Distribution of Crude Oil

Futures Prices During the Gulf Crisis

Growth, Political Instability, and

the Defense Burden

Foreign Exchange Policy, Monetary Policy, and Capital Market Liberalization in Korea

The Political Economy of the Won:

U.S.-Korean Bilateral Negotiations on Exchange Rates

Import Demand and Supply with Relatively

Few Theoretical or Empirical Puzzles The Liquidity Premium in Average Interest
Rates

The Power of Cointegration Tests
$\underline{\operatorname{AUTHOR}(s)}$

Reuven Glick

Kenneth Rogoff

Douglas A. Irwin

Kenneth D. West

Hali J. Edison

Dongchul Cho

Julia Campos

Neil R. Ericsson

David F. Hendry

Jaime Marquez

Geert J. Almekinders

Sylvester C.W. Eijffinger

William R. Melick

Charles P. Thomas

Stephen Brock Blomberg

Deborah J. Lindner

Deborah J. Lindner

Andrew M. Warner

Wilbur John Coleman II Christian Gilles

Pamela Labadie

Jeroen J.M. Kremers

Neil R. Ericsson

Juan J. Dolado

Please address requests for copies to International Finance Discussion Papers, Division of International Finance, Stop 24, Board of Governors of the Federal
Reserve System, Washington, D.C. 20551. 
IFDP

NUMBER

430 The Adequacy of the Data on U.S. International Financial Transactions:

A Federal Reserve Perspective

429 Whom can we trust to run the Fed?

Theoretical support for the founders views

428 Stochastic Behavior of the World Economy under Alternative Policy Regimes

427 Real Exchange Rates: Measurement and Implications for Predicting U.S. External Imbalances
Central Banks' Use in East Asia of Money Market Instruments in the Conduct of Monetary Policy

Purchasing Power Parity and Uncovered Interest Rate Parity: The United States 1974 - 1990

Fiscal Implications of the Transition from Planned to Market Economy

Does World Investment Demand Determine U.S. Exports?

The Autonomy of Trade Elasticities: Choice and Consequences

German Unification and the European Monetary System: A Quantitative Analysis

Taxation and Inflation: A New Explanation for Current Account Balances
Lois E. Stekler

Edwin M. Truman

Jon Faust

Joseph E. Gagnon

Ralph W. Tryon

Jaime Marquez

Robert F. Emery

Hali J . Edison William R. Melick

R. Sean Craig Catherine L. Mann

Andrew M. Warner

Jaime Marquez

Gwyn Adams Lewis Alexander Joseph Gagnon

Tamim Bayoumi Joseph Gagnon 